\title{
Broncopneumopatia cronica ostruttiva (BPCO)
}

\author{
C. Terzano, A. Petroianni
}

\section{Introduzione}

La broncopneumopatia cronica ostruttiva (BPCO) è una delle maggiori cause di morbilità e mortalità in tutto il mondo. A causa dell'elevata prevalenza e della possibilità di essere una patologia altamente invalidante, i costi della BPCO possono rappresentare un importante impegno economico e sociale per la spesa sanitaria.

La BPCO affligge 600 milioni di uomini e donne nel mondo. In Italia è la quarta causa di malattia cronica, colpisce 4 milioni di persone, con circa 130000 ricoveri ospedalieri all'anno, ed è gravata da oltre 18000 decessi l'anno.

La BPCO è la quarta causa di morte negli USA, subito dopo le patologie cardiache, tumori e malattie cerebrovascolari, e risulta in continua crescita, con un aumento della mortalità negli ultimi 30 anni del $+163 \%$. In Italia, dopo i 65 anni, la BPCO colpisce il 18\% degli uomini e l'11\% delle donne. La sopravvivenza media a dieci anni, in questa fascia d'età, che sarebbe del $72 \%$ per la popolazione generale, scende al $20-40 \%$ nei pazienti affetti da grave BPCO.

Tra costi diretti e indiretti la spesa media annua per paziente si aggira intorno ai 1300 euro. A differenza di altre patologie quali ictus, infarto miocardico e tumori, la BPCO è in continua crescita: secondo l'OMS (Organizzazione Mondiale della Sanità), nei prossimi anni è destinata a diventare la terza causa di malattia cronica nel mondo.

La malattia riveste pertanto una grande importanza dal punto di vista epidemiologico e di impegno delle risorse sanitarie.

Nonostante le numerose campagne di sensibilizzazione e di prevenzione, il fumo di sigaretta risulta ancora la principale causa della BPCO. La conseguente attenzione per questa patologia da parte delle organizzazioni sanitarie mondiali e della ricerca farmaceutica hanno ampliato, negli ultimi anni, la conoscenza sulla patogenesi, fisiopatologia, diagnostica e terapia della malattia stessa.

Gli esami funzionali spirometrici rappresentano il cardine per la diagnosi e per il monitoraggio della malattia. Nella classificazione della BPCO il valore del $\mathrm{FEV}_{1}$ e degli indici di ristagno aereo, quali la FRC e la RV contribuiscono, insieme al quadro clinico, a determinare lo stadio della malattia e a monitorarne la progressione. 


\section{Definizione}

La definizione di broncopneumopatia cronica ostruttiva (BPCO) è stata modificata nel corso degli anni, grazie alle sempre più approfondite conoscenze anatomo-patologiche, funzionali ed immunologiche che caratterizzano tale patologia.

Dalla brillante intuizione di Laennec che, nel 1827, riportò nel suo Treatise on the diseases of the Chest and on mediate auscultation come nella bronchite cronica "l'aria fuoriesce dai polmoni molto più lentamente rispetto alle condizioni normali dell'organo" e che "ciò sembra indicare o una comunicazione più difficoltosa tra l'aria contenuta nelle cellule aeree e quella contenuta nei bronchi (bronchiolite e ostruzione bronchiolare, n.d.r.), oppure una diminuita elasticità delle vie aeree (perdita di ritorno elastico del polmone, n.d.r.)", il termine di BPCO (o, come definita dalla scuola anglosassone, COPD: Chronic Obstructive Pulmonary Disease) è stato utilizzato per la prima volta nel 1962 (American Thoracic Society, ATS) per definire una "ostruzione cronica delle vie aeree di incerta eziologia”. Successivamente, nel 1987, l'ATS ha definito i confini della malattia precisando che la BPCO (COPD) è "una patologia caratterizzata da ostruzione del flusso espiratorio che non si modifica significativamente nel corso del tempo", differenziandola quindi dall'asma bronchiale, che risulta caratterizzata da ampia variabilità dei flussi espiratori.

Nel 1995, all'ostruzione persistente delle vie aeree, l'European Respiratory Society (ERS) ha introdotto il concetto che "la limitazione al flusso aereo risulta lentamente progressiva ed irreversibile, dovuta in parte ad interessamento delle vie aeree ed in parte a modificazioni parenchimali (enfisema polmonare)".

Infine, nel progetto GOLD (2003) è stato inserito il concetto di possibile parziale reversibilità della ostruzione bronchiale, definendo la BPCO come una "sindrome caratterizzata da una limitazione del flusso aereo espiratorio non completamente reversibile né spontaneamente né con trattamento farmacologico. In genere tale riduzione del flusso aereo espiratorio è progressiva e si associa ad una risposta infiammatoria broncopolmonare dovuta alla inalazione di particelle o gas tossici”.

Pertanto sembra oggi corretto definire la BPCO sinteticamente come una malattia caratterizzata da ostruzione irreversibile o non completamente reversibile del flusso aereo, caratterizzata da una limitazione funzionale progressiva ed associata ad una persistente risposta infiammatoria dovuta alla inalazione di particelle o gas irritanti.

L'intera gamma dei sintomi, le anormalità funzionali e le complicanze della BPCO possono essere spiegate sulla base della presenza continua della risposta infiammatoria.

L'enfisema polmonare, compreso nella definizione di BPCO e di cui se ne parlerà ampiamente in seguito, rappresenta un'entità anatomo-patologica caratterizzata da un aumento permanente e distruttivo dagli spazi aerei distali ai bronchioli terminali. Pertanto il concetto di enfisema polmonare 
esprime solo una parte delle alterazioni morfologiche che si osservano nella BPCO.

Il rapporto tra le tre forme cliniche ostruttive (asma, bronchite cronica, enfisema) è ben documentato dal diagramma in Figura 1. Esso mostra le strette interrelazioni tra le diverse forme, con diverso contributo patogenetico all'ostruzione delle vie aeree, reversibile ed irreversibile. Le differenti forme di patologia ostruttiva con le loro caratteristiche fisiopatologiche possono coesistere nello stesso paziente.

L'ostruzione del flusso aereo presente nei soggetti con bronchiectasie, fibrosi cistica o tubercolosi non rientra nella definizione di BPCO, tranne nelle eventualità che la BPCO si sovrapponga a tali malattie, contribuendo in maniera autonoma alla irreversibile ostruzione del flusso aereo.

Nella Tabella 1 sono riportate le differenze fra asma e BPCO.

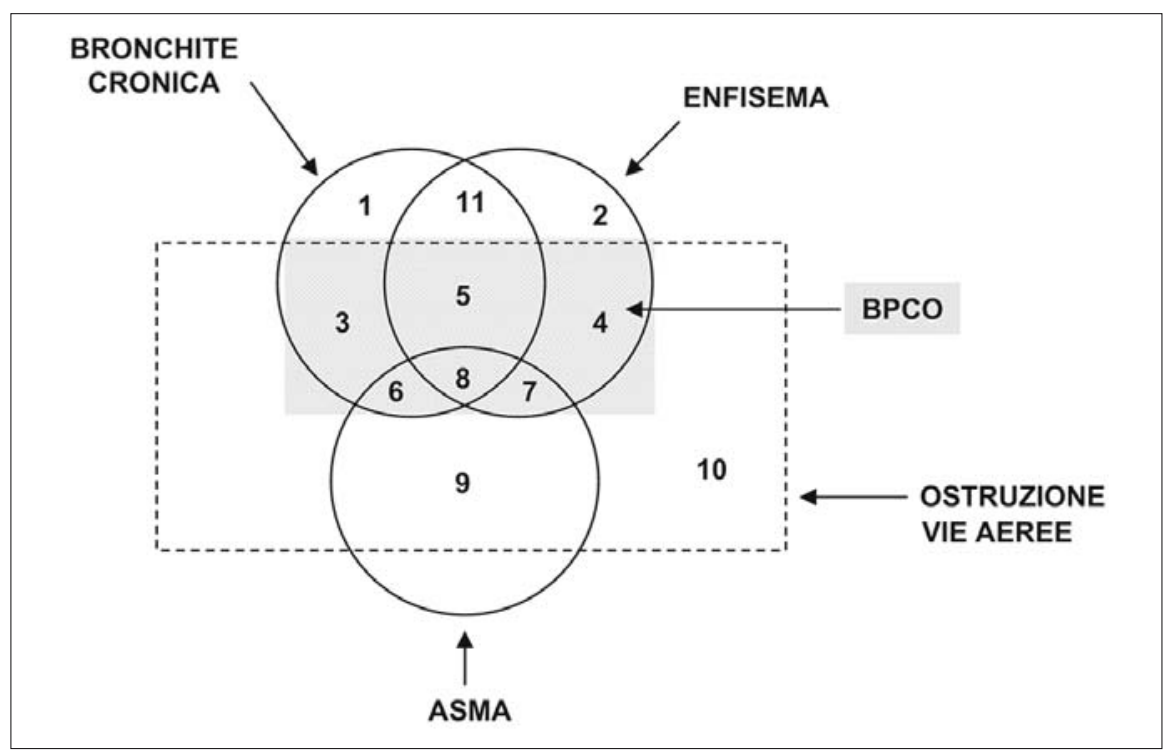

Fig. 1. Diagramma di Venn modificato. Il diagramma non è proporzionale: le singole aree non correlano con le dimensioni delle singole patologie. Nel gruppo BPCO non sono considerati i pazienti con asma la cui ostruzione è completamente reversibile (area 9). Pertanto l'asma, nonostante faccia parte del diagramma, deve essere considerata come una patologia a sé, distinta dalle altre. Le aree 6, 7 e 8 identificano l'ostruzione parzialmente reversibile. L'area 1 identifica la bronchite cronica semplice. La bronchite cronica e l'enfisema con ostruzione al flusso sono generalmente associate (area 5). Alcuni pazienti con asma possono presentare un'associazione con la bronchite cronica e l'enfisema (area 8). I soggetti affetti da asma bronchiale possono sviluppare bronchite cronica se esposti al fumo di sigaretta ed altri irritanti (area 6). I soggetti con bronchite cronica e/o enfisema senza ostruzione al flusso aereo non sono classificati come BPCO (aree 1, 2 e 11). Pazienti affetti da bronchiectasie, bronchiolite o fibrosi cistica non sono inclusi nella definizione della BPCO (area 10) 
Tabella 1. Quadro riassuntivo delle differenze fra asma e BPCO. Nell'asma, l'infiammazione delle vie aeree è caratterizzata dall'infiammazione eosinofila che interessa tutte le vie aeree con esclusione del parenchima polmonare ed è strettamente collegata all'iperreattività bronchiale. Sono evidenti numerosi eosinofili attivati e degranulati nel liquido di lavaggio broncoalveolare (BAL), nelle biopsie bronchiali e nell'espettorato indotto. Neutrofilia può tuttavia essere presente nelle gravi forme di asma. Si osserva inoltre un aumento dei linfociti $C D 4^{+}$. II processo infiammatorio interessa tutte le vie aeree con esclusione del parenchima polmonare. La fibrosi si osserva anche nei pazienti con asma lieve e di breve durata. L'iperreattività bronchiale rappresenta la caratteristica fisiologica dell'asma ed è strettamente collegata all'infiammazione eosinofila. Nella BPCO, I'infiammazione è caratterizzata dalla presenza di un elevato numero di neutrofili (infiammazione neutrofila) nelle vie aeree, così come testimoniato dal BAL e dall'espettorato indotto. La biopsia bronchiale evidenzia infiltrazione da parte di cellule mononucleate, linfociti $\mathrm{TCD}^{+}$e particolarmente $\mathrm{CD} 8^{+}$piuttosto che neutrofili, a testimonianza del fatto che i neutrofili transitano rapidamente dalla circolazione all'interno del lume delle vie aeree.I macrofagi, notevolmente aumentati di numero e concentrati nelle zone centroacinari dove l'enfisema è più marcato, sono attivati dal fumo di sigaretta ed altri irritanti e rilasciano fattori chemotattici per i neutrofili ed enzimi proteolitici. All'opposto di quanto si osserva nell'asma, la maggior parte delle modificazioni patologiche avvengono a livello delle piccole vie aeree, a livello delle quali è presente fibrosi e bronchiolite obliterante. L'ipersecrezione mucosa rappresenta una caratteristica della BPCO ed è associata a metaplasia delle ghiandole sottomucose e delle globet cell. Infine la distruzione del parenchima rappresenta una elemento importante che conduce all'ostruzione al flusso aereo attraverso la compressione dinamica delle vie aeree e alla riduzione del massimo flusso espiratorio. I broncodilatatori, contrariamente a quanto si osserva nell'asma

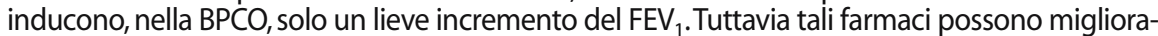
re la sintomatologia dei pazienti con BPCO attraverso la riduzione dell'iperinflazione polmonare e, quindi, della dispnea. I broncodilatatori aumentano inoltre, nella BPCO, la tolleranza all'esercizio fisico. I farmaci broncodilatatori più efficaci nella BPCO sono rappresentati dagli anticolinergici, fra i quali un nuovo farmaco, il tiotropio bromuro, è caratterizzato da una lunga durata d'azione (24 ore), offrendo la possibilità di poter essere somministrato solo una volta al giorno. All'opposto di quanto si osserva nella $\mathrm{BPCO}$, i $\beta 2$-agonisti risultano più efficaci nella terapia dell'asma. In contrasto all'infiammazione eosinofila tipica dell'asma, marcatamente soppressa dai glucocorticoidi, questi ultimi non svolgono alcun effetto sull'infiammazione neutrofila tipica della BPCO. All'opposto i glucocorticoidi prolungano, in vitro, la sopravvivenza dei neutrofili inibendone I'apoptosi, contrariamente a quanto osservato a carico degli eosinofili nei quali, invece, l'apoptosi è favorita dall'uso di glucocorticoidi. Nonostante i glucocorticoidi non svolgano alcun effetto sul declino della funzione respiratoria nella BPCO, è stato osservato che, quando utilizzati ad alte dosi, possono lievemente ridurre la frequenza delle riacutizzazioni e migliorare la qualità della vita. Infine, una percentuale di circa il $10 \%$ dei pazienti con BPCO, presenta risposta clinica ai glucocorticoidi da imputare, verosimilmente, a concomitante asma. Le discrepanze osservate nel trattamento con glucocorticoidi delle forme acute e croniche della BPCO, possono essere collegate alle differenze nella risposta infiammatoria quali, ad esempio, l'aumentato numero degli eosinofili e l'edema delle vie aeree tipiche delle riacutizzazioni della BPCO

\begin{tabular}{|c|c|c|}
\hline & Asma & $\mathrm{BPCO}$ \\
\hline Cellule infiammatorie & $\begin{array}{l}\text { Mastcellule, eosinofili, } \\
\text { macrofagi } \uparrow, \text { cellule CD4 }{ }^{+} \text {(Th2) }\end{array}$ & $\begin{array}{l}\text { Neutrofili, macrofagi } \uparrow \uparrow, \\
\text { cellule } \mathrm{CD}^{+}(\mathrm{TC})\end{array}$ \\
\hline $\begin{array}{l}\text { Mediatori } \\
\text { dell'infiammazione }\end{array}$ & $\begin{array}{l}\text { Istamina, LTB }{ }_{4} \text {, RANTES, IL-4, } \\
\text { IL-5, IL- } 13 \text {, stresso ossidativo } \uparrow\end{array}$ & $\begin{array}{l}\mathrm{LTB}_{4} \text {, IL- } 8, \mathrm{TNF}-\alpha \text {, stress } \\
\text { ossidativo } \uparrow \uparrow \uparrow\end{array}$ \\
\hline $\begin{array}{l}\text { Effetti } \\
\text { dell'infiammazione }\end{array}$ & $\begin{array}{l}\text { Tutte le vie aeree } \\
\uparrow \uparrow \uparrow \text { iperresponsività bronchiale } \\
\text { Danno epiteliale } \\
\uparrow \text { Fibrosi } \\
\text { Parenchima non coinvolto } \\
\uparrow \text { Secrezione mucosa }\end{array}$ & $\begin{array}{l}\text { Piccole vie aeree } \\
\uparrow \downarrow \text { iperresponsività bronchiale } \\
\text { Metaplasia epiteliale } \\
\uparrow \uparrow \uparrow \text { Fibrosi } \\
\text { Distruzione del parenchima } \\
\uparrow \uparrow \uparrow \uparrow \text { Secrezione mucosa }\end{array}$ \\
\hline $\begin{array}{l}\text { Risposta ai } \\
\text { broncodilatatori }\end{array}$ & $\uparrow \uparrow \uparrow$ & $\uparrow$ \\
\hline $\begin{array}{l}\text { Risposta } \\
\text { ai glucocorticoidi }\end{array}$ & $\uparrow \uparrow \uparrow$ & $\uparrow \downarrow$ \\
\hline
\end{tabular}




\section{Epidemiologia e fattori di rischio}

La BPCO in Italia è al quarto posto come causa di malattia cronica. Negli ultimi quindici anni la frequenza di mortalità standardizzata per età è aumentata del $50 \%$. La prevalenza e la mortalità sono più alte per il sesso maschile, anche se negli ultimi anni si è osservato un aumento considerevole dei casi di BPCO nelle donne per la diffusione in tale gruppo dell'abitudine tabagica.

Per comprendere l'impatto economico della patologia è utile soffermarsi brevemente sui costi diretti (accertamenti diagnostici, visite mediche, ricoveri in emergenza, ospedalizzazioni, trattamenti farmacologici) e indiretti (giornate lavorative perse, mortalità precoce) attribuiti alla BPCO.

Un metodo proposto per misurare la mortalità e la disabilità attribuibile ad una specifica malattia è la misura del DALY (Disability-Adjusted Life Year). I DALYs per una specifica condizione morbosa sono la somma degli anni di vita persi a causa della mortalità precoce e gli anni di vita vissuta con disabilità, adattata alla gravità della disabilità.

Nel 1990 la BPCO era a livello mondiale la dodicesima causa principale di DALYs persa, responsabile per il 2,1\% del totale. Secondo alcune proiezioni la BPCO nel 2020 sarà la quinta causa principale di DALYs perse, subito dopo la malattia cardiaca ischemica, depressione, incidenti stradali e malattie cerebrovascolari.

I fattori di rischio per la BPCO possono essere divisi in irritanti ambientali e fattori predisponenti genetici, e spesso la malattia è frutto dell'interazione di entrambi questi fattori (Tabella 2).

Come per la bronchite cronica, anche per la BPCO tra i fattori di rischio il più importante è sicuramente il fumo di sigaretta. Infatti più dell' $85 \%$ dei casi di BPCO sono da riferire al fumo di sigaretta. I fumatori, rispetto ai non fumatori, presentano una mortalità per BPCO più alta ed una prevalenza e incidenza maggiore per tosse produttiva e altri sintomi respiratori.

Inoltre l'età in cui si inizia a fumare, il numero di pacchetti/anno fumati, e lo stato attuale di fumatore risultano predittivi della mortalità per BPCO.

In diversi studi è stato osservato come la prevalenza della BPCO sia più alta nei paesi dove il fumo di sigaretta è più diffuso, mentre risulta più bassa nei paesi dove il consumo di tabacco pro capite è più basso.

Tabella 2. Fattori di rischio per la BPCO

\section{Fattori ambientali}

- Fumo di sigaretta

- Inquinamento ambientale

- Esposizioni occupazionali

- Infezioni ricorrenti

- Livello socioeconomico
Fattori legati all'ospite

- Deficit di alfa1 antitripsina

- Iperresponsività bronchiale

- Sviluppo polmonare 
Il grado di ostruzione, misurato tramite l'esame spirometrico, correla bene con il numero di sigarette fumate. Tuttavia non tutti i fumatori presentano una BPCO. E stato infatti stimato che circa il $15 \%$ dei soggetti fumatori sviluppano una BPCO clinicamente significativa.

Il normale declino del $\mathrm{FEV}_{1}$ con l'età risulta più rapido nei fumatori (Fig. 2).

Altre documentate cause di BPCO includono l'inalazione prolungata di polveri e vapori chimici in ambienti lavorativi e l'inquinamento ambientale indoor e outdoor, anche se il ruolo degli inquinanti atmosferici nel favorire la BPCO è ancora poco chiaro. Infatti non risultano ancora ben evidenti i reali rapporti tra effetti a breve termine, esposizione a picchi di concentrazione e concentrazioni di fondo del particolato atmosferico e BPCO.

Lo stato socioeconomico è stato proposto da alcuni autori come fattore predisponente, presumibilmente perché esprime il grado di esposizione a inquinanti ambientali outdoor e indoor, affollamento nelle abitazioni, malnutrizione ed altri fattori collegati.

Tra i fattori predisponenti legati all'ospite risultano particolari deficit genetici (alfa1-antitripsina) ed uno stato di atopia ed iper-responsività bronchiale.

Anche le infezioni respiratorie ricorrenti possono predisporre alla genesi della BPCO.

L'“ipotesi olandese” suggerita da Orie et al. nel 1961 propone infine la possibilità che esistano graduali step di patologia ostruttiva che parte da un quadro di iper-reattività bronchiale individuale. Risulta tuttavia difficile, ancora oggi, stabilire se l'iper-reattività bronchiale rappresenta un principale fattore di rischio per la BPCO oppure una conseguenza della malattia.

In alcuni studi la presenza di eosinofili nell'espettorato, iper-responsività bronchiale e broncospasmo è stata correlata ad un più rapido declino del $\mathrm{FEV}_{1}$.

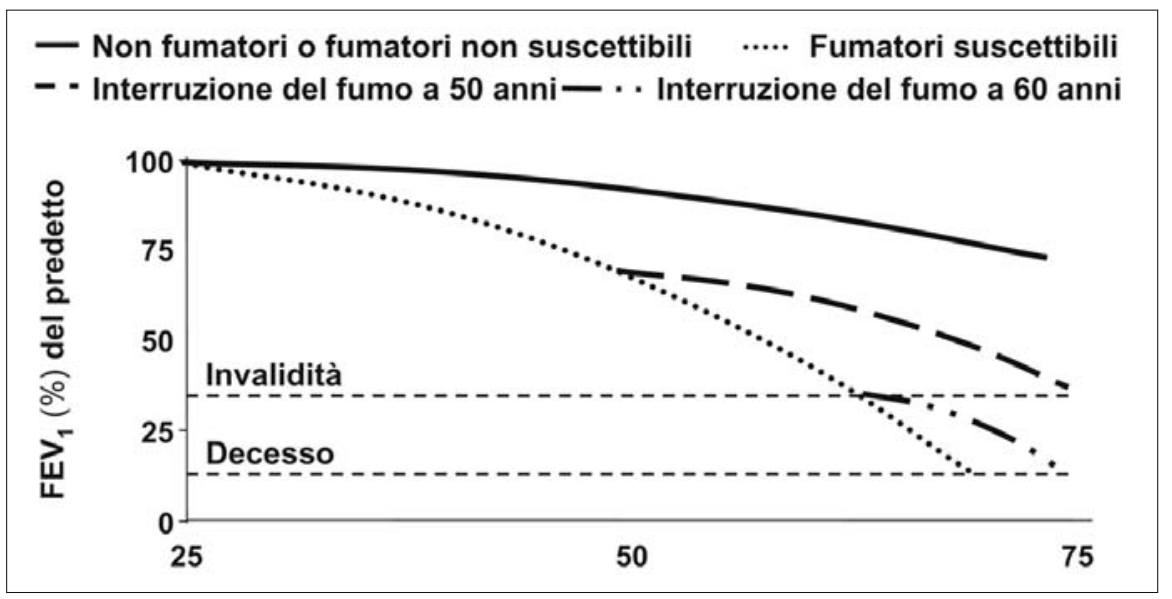

Fig. 2. Declino della funzione respiratoria nella BPCO. I pazienti affetti da BPCO mostrano un declino del $\mathrm{FEV}_{1}$ da 50 a $90 \mathrm{ml} / \mathrm{anno}$. I soggetti non fumatori sani al di sopra dei 30 anni mostrano un declino del FEV 1 di 20-30 ml/anno (da Fletcher C, Peto $\mathrm{R}$ (1977) The natural history of chronic airflow obstruction. Br Med J 1:1645-1648) 
Anche un anomalo sviluppo dell'apparato respiratorio può favorire lo sviluppo di patologia ostruttiva cronica, mentre il fumo durante la gravidanza può predisporre il feto a patologie respiratorie, influenzando lo sviluppo e la crescita polmonare in utero.

In relazione a possibili geni coinvolti nello sviluppo della $\mathrm{BPCO}$, sono state formulate alcune ipotesi per lo stato di secretore ABO, per l'epossido idrolasi microsomiale, la glutatione S-transferasi, l'alfal-antichimotripsina, la citochina TNF-alfa e l'instabilità del DNA microsatellite. Tuttavia non esistono al momento conferme clinico-genetiche-epidemiologiche su tali correlazioni.

Per concludere, anche il sesso sembra essere un fattore di rischio. Le donne, per la particolare conformazione anatomica delle vie aeree e per le caratteristiche di deposizione delle particelle nelle vie aeree, risultano più suscettibili degli uomini all'effetto dannoso del fumo di sigaretta.

\section{Patogenesi}

La BPCO è una malattia infiammatoria cronica delle vie aeree, caratterizzata da una limitazione al flusso progressiva e non reversibile.

L'ostruzione cronica al flusso delle vie aeree risulta determinata prevalentemente da alterazioni della struttura delle piccole vie aeree e dalla distruzione del parenchima polmonare (enfisema) (Fig. 3).

Infatti l'infiammazione cronica bronchiale, favorendo il rimodellamento e il restringimento delle piccole vie aeree e, a livello parenchimale, la perdita della struttura alveolare, determina la riduzione del ritorno elastico polmonare con conseguente precoce chiusura delle piccole vie aeree durante l'atto espiratorio.

Il processo infiammatorio, inoltre, riduce i meccanismi di difesa utili nel limitare la distruzione tissutale ed altera i meccanismi riparativi favorendo la persistenza del danno broncopolmonare. I risultati di tale quadro sono rappresentati

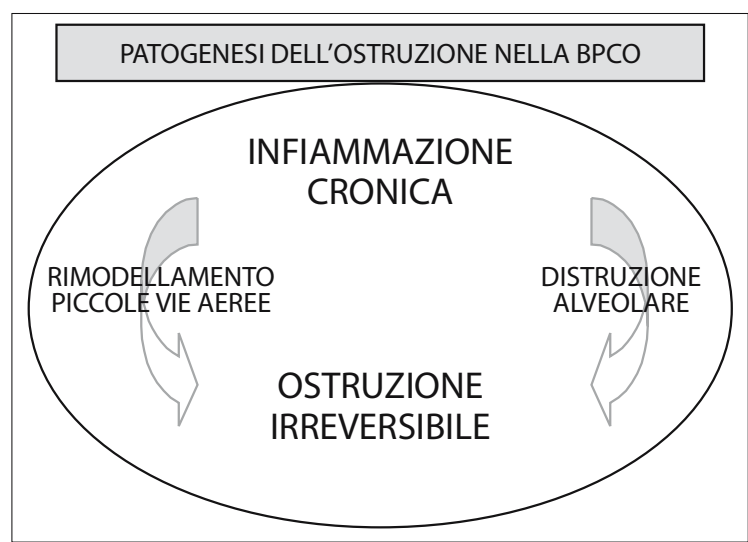

Fig. 3. Nella BPCO lo stato infiammatorio cronico determina alterazioni anatomiche che conducono ad un quadro di ostruzione irreversibile o scarsamente reversibile 
da una iperproduzione mucosa, contrazione delle vie aeree, distruzione della struttura alveolare e modificazioni vascolari polmonari.

Nella BPCO l'ipersecrezione mucosa è indotta dalla stimolazione delle ghiandole mucosecernenti, che appaiono di dimensioni aumentate, e dalla proliferazione delle cellule mucipare da parte dei mediatori della flogosi.

Lo spasmo muscolare della parete bronchiale (broncocostrizione) è ascrivibile alle alterazioni a carico della mucosa respiratoria, che rendono più esposte le terminazioni nervose sensitive in grado di evocare, per via riflessa vagale, la contrazione della muscolatura liscia bronchiale.

Inoltre è stato osservato come, a causa dell'insulto flogistico sulle pareti bronchiali, si produce una deplezione dei recettori $\beta 2$-adrenergici collocati a livello del muscolo liscio bronchiale, deputati ad un ruolo di protezione nei confronti di agenti broncocostrittori.

In questi pazienti la conseguenza è pertanto un cronico incremento del tono broncomotore. Tale condizione può favorire la creazione di un circolo vizioso che tenderà a sostenere il fenomeno della broncocostrizione, rendendo il paziente più sensibile ai molteplici fattori irritanti di natura chimica, fisica o biologica presenti nell'aria inalata.

L'infiammazione, l'edema della mucosa e l'iperproduzione di muco possono causare una cospicua riduzione del calibro del lume dei piccoli bronchi e dei bronchioli. In seguito, l'organizzazione dell'essudato da parte di tessuto di granulazione e la successiva evoluzione cicatriziale, possono determinare una bronchiolite fibrosa obliterante.

L'analisi patogenetica della BPCO richiede quindi una approfondita valutazione del processo infiammatorio per valutare sia la componente cellulare coinvolta, sia i mediatori infiammatori, al fine di comprendere a pieno i processi sottostanti l'evoluzione clinica della malattia (Fig. 4).

Nella BPCO si osserva un aumento dei neutrofili, macrofagi e linfociti CD8+ in varie parti del polmone. In alcuni pazienti vi può essere anche un aumento degli eosinofili, particolarmente durante le riacutizzazioni. Molti studi sottolineano la stretta correlazione tra il numero di cellule infiammatorie presenti nell'albero bronchiale e la severità della malattia (Fig. 5).

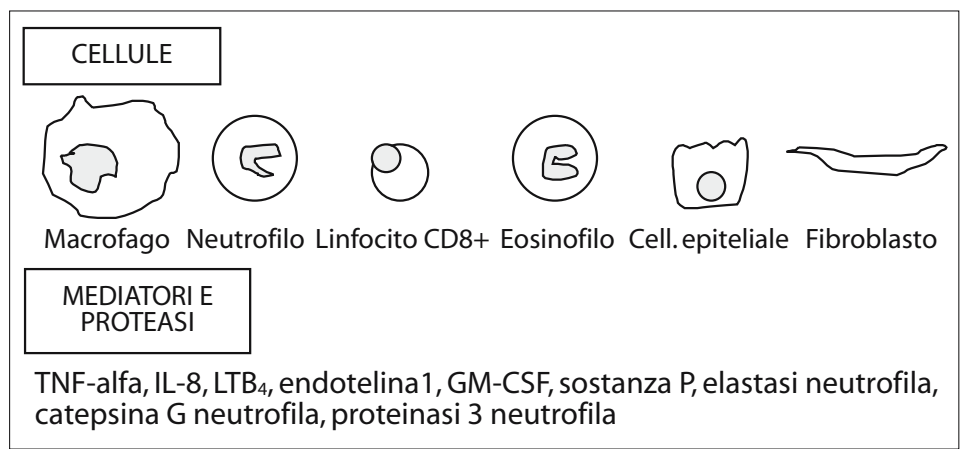

Fig. 4. I differenti tipi cellulari e mediatori infiammatori coinvolti nella BPCO 


\begin{tabular}{|l|l|}
\hline \multicolumn{1}{|c|}{ CELLULE INFIAMMATORIE NELLA BPCO } & LOCALIZZAZIONE \\
\hline $\begin{array}{l}\text { MACROFAGI } \\
\text { LINFOCITIT CD8+ } \\
\text { NEUTROFILI (in stadio grave) } \\
\text { EOSINOFILI (in alcuni pazienti) }\end{array}$ & VIE AEREE CENTRALI \\
\hline $\begin{array}{l}\text { MACROFAGI } \\
\text { LINFOCIITI CD8+ } \\
\text { EOSINOFILI (in alcuni pazienti) }\end{array}$ & PICCOLE VIE AEREE \\
\hline $\begin{array}{l}\text { MACROFAGI } \\
\text { LINFOCIIT CD8+ } \\
\text { NEUTROFILI }\end{array}$ & PARENCHIMA \\
\end{tabular}

Fig. 5. I diversi tipi di cellule infiammatorie e la loro distribuzione lungo le vie aeree e parenchima polmonare

Il numero dei neutrofili risulta aumentato nell'espettorato e nel BAL di pazienti con BPCO e in fumatori asintomatici, aumentando ulteriormente durante le riacutizzazioni. Essi producono elastasi neutrofila, catepsina G neutrofila e proteinasi 3 neutrofila, che contribuiscono alla distruzione del tessuto polmonare ed alla ipersecrezione mucosa.

I macrofagi risultano aumentati di numero nelle grandi e piccole vie aeree e nel parenchima polmonare e rilasciano mediatori che promuovono l'infiammazione neutrofila (TNF-alfa, IL-8, $\mathrm{LTB}_{4}$ ). Nei pazienti con enfisema i macrofagi sono prevalentemente localizzati nei siti di distruzione delle pareti alveolari.

Studi su biopsie bronchiali in pazienti con BPCO hanno dimostrato un aumento dei linfociti $\mathrm{T}$, in particolare dei CD8+ citotossici.

Il ruolo dei linfociti T CD8+ citotossici nella BPCO non è ancora completamente chiaro; il loro numero risulta aumentato, favorendo il danno cellulare alveolare tramite il rilascio di: a) perforine, sostanze che producono lesioni perforative sulla membrana della cellula bersaglio e ne provocano la morte per lisi osmotica; le perforine producono pori nella membrana delle cellule attraverso i quali enzimi proteolitici - granzimi - passano dalla cellula T citotossica alla cellula bersaglio; almeno uno di questi enzimi proteolitici attiva l'enzima caspasi, che media l'apoptosi nella cellula bersaglio; e b) TNF-alfa (citochina pro-infiammatoria).

Gli eosinofili possono essere aumentati a livello delle vie aeree dei soggetti che presumibilmente presentano anche una componente asmatica coesistente.

L'aumento della proteina cationica eosinofila e della perossidasi eosinofila nell'espettorato suggeriscono la degranulazione degli eosinofili in seguito alla presenza della elastasi neutrofila. Durante le riacutizzazioni il loro numero risulta infatti aumentato.

Anche le cellule epiteliali alveolari sono implicate nell'attivazione del processo infiammatorio con produzione di mediatori e molecole di adesione per i neutrofili.

Tra i mediatori infiammatori coinvolti nella BPCO particolare attenzione è stata posta al TNF-alfa, $\mathrm{LTB}_{4}$ e IL-8, i quali risultano tutti aumentati nella BPCO. 
Il TNF-alfa attiva la trascrizione del fattore nucleare NF-kB che attiva, a sua volta, il gene per IL-8 nelle cellule epiteliali e nei macrofagi. Inoltre il TNF-alfa gioca un ruolo importante nella cachessia dei soggetti BPCO severi. Il LTB 4 deriva dai macrofagi alveolari ed è un potente fattore chemiotattico per i neutrofili. L'IL-8 è un agente chemiotattico selettivo per i neutrofili, secreta dai macrofagi, cellule epiteliali e neutrofili stessi e gioca un ruolo primario nell'attivazione dei neutrofili ed eosinofili.

Altri mediatori ritenuti coinvolti nell'infiammazione della BPCO sono rappresentati dai fattori di crescita TGF-beta (fattore di crescita trasformante) e EGF (fattore della crescita epidermico), l'ET-1 (endotelina), dal GM-CSF (fattore stimolante le colonie granulocite-macrofagiche), dall'MCP-1 (proteina chemiotattica macrofagica), MIP-1beta (proteina infiammatoria macrofagica), e diversi neuropeptidi (sostanza P, VIP).

Poiché il processo infiammatorio delle vie aeree risulta al centro della patogenesi della BPCO, la terapia antinfiammatoria è stata ritenuta fondamentale nel controllo dei sintomi, nella prevenzione delle riacutizzazioni e nel rallentare la progressione della malattia. Tuttavia nei soggetti con BPCO si è osservata una scarsa risposta dell'infiammazione alla terapia corticosteroidea rispetto alla patologia asmatica, dove l'infiammazione è particolarmente sensibile a tale tipo di trattamento.

Ciò è dovuto prevalentemente e verosimilmente alla diversa popolazione cellulare e ai mediatori coinvolti nel processo infiammatorio nella BPCO e nell'asma (Tabella 1).

Strettamente associati all'infiammazione, altri due processi sono ritenuti fondamentali nella patogenesi della BPCO: lo squilibrio del sistema proteinasi/antiproteinasi e lo stress ossidativo. Questi ultimi possono essere generati dal processo infiammatorio stesso o attivati da fattori ambientali (fumo di sigaretta) o genetici (deficit di antiproteinasi).

L'elastina, bersaglio dell'elastasi neutrofila, è il maggior componente della parete alveolare e frammenti di questa possono ampliare la risposta infiammatoria, agendo come fattore chemiotattico per macrofagi e neutrofili. Un eventuale squilibrio del sistema proteinasi/antiproteinasi condurrebbe ad una distruzione marcata del tessuto polmonare.

Ulteriori proteinasi coinvolte nella BPCO sono rappresentate dalla catepsina neutrofila G, la proteinasi 3 neutrofila, le catepsine (B, L, S) rilasciate dai macrofagi e dalle metalloproteinasi. Le proteinasi sono in grado di degradare l'elastina ed il collagene. Inoltre alcune proteinasi (elastasi neutrofile) possono indurre secrezione di muco ed iperplasia delle ghiandole mucose.

Nei soggetti con BPCO la produzione di agenti ossidanti risulta aumentata. $\mathrm{L}^{\prime} \mathrm{H}_{2} \mathrm{O}_{2}$ e l'NO risultano più elevati nel respiro del paziente con $\mathrm{BPCO}$ riacutizzata. L'isoprostano F2-alfa-III, un isomero della prostaglandina, generato dalla perossidazione dell'acido arachidonico, risulta aumentato nel respiro e nelle urine dei pazienti BPCO. Tali agenti ossidanti possono reagire con numerose molecole (proteine, lipidi, acidi nucleici), danneggiandole e favo- 
rendo la loro disfunzione. Inoltre lo stress ossidativo contribuisce ad inattivare alcune antiproteinasi ed attivare proteinasi, promovendo l'infiammazione ed il danno tissutale.

Nei pazienti con BPCO l'essudato infiammatorio interessa l'epitelio e le ghiandole, con prevalenza di cellule macrofagiche e linfociti T CD8+. Inoltre si osserva un aumento delle globet cells e cellule squamose (metaplasia) e una disfunzione delle ciglia con grave danno e/o perdita delle stesse. Le ghiandole mucose della sottomucosa si ipertrofizzano insieme alla componente muscolare liscia bronchiale; il tessuto cartilagineo degenera e vi è iperproduzione di muco. Questi cambiamenti patologici a livello delle grandi e medie vie aeree sono responsabili della sintomatologia tipica della BPCO: tosse cronica ed espettorato.

L'interessamento infiammatorio delle vie aeree periferiche, rappresentate dai bronchi con diametro inferiore a $2 \mathrm{~mm}$ (bronchioli), determina il declino della funzione polmonare nella BPCO. L'infiammazione dà luogo ad un infiltrato interessante la parete e il lume bronchiale, metaplasia squamosa dell'epitelio, edema della mucosa e iperproduzione di muco, che contribuiscono al restringimento del lume bronchiale.

Il continuo danno infiammatorio e il conseguente processo riparativo provocano un "rimodellamento" strutturale della parete delle vie aeree, con aumento della componente collagena e fibrotica, che restringe il lume e determina una ostruzione fissa delle vie aeree. Nella BPCO le vie aeree periferiche diventano così il sito maggiore dell'ostruzione.

Il parenchima polmonare comprende la superficie di scambio dei gas (bronchioli respiratori e alveoli) ed i capillari polmonari. L'alterazione più frequente del parenchima polmonare nei pazienti con BPCO è l'enfisema centrolobulare, caratterizzato dalla dilatazione e distruzione dei bronchioli respiratori. L'enfisema centrolobulare inizialmente interessa più frequentemente le regioni polmonari apicali per poi coinvolgere l'intero polmone ed il letto capillare. L'enfisema panacinare, che interessa l'intero acino, è caratteristico dei soggetti relativamente giovani con deficit di alfa1-antitripsina e coinvolge inizialmente i lobi inferiori.

Le alterazioni vascolari sono caratterizzate da un ispessimento della parete dei vasi che inizia in una fase precoce della malattia, quando la funzione polmonare è ancora ben conservata e la pressione del piccolo circolo è normale. L'ispessimento dell'intima è seguito dall'aumento della componente muscolare liscia e dall'infiltrazione di cellule infiammatorie, macrofagi e linfociti CD8+, a livello della parete vascolare.

\section{Valutazione della funzionalità respiratoria}

I test di funzionalità respiratoria assumono particolare importanza nella valutazione dell'ostruzione delle vie aeree.

Quest'ultima può essere infatti conseguenza dell'edema e della ipersecrezione cronica (bronchite cronica), della contrazione della muscolatura liscia bronchia- 
le (asma) oppure della riduzione della forza di retrazione elastica del tessuto polmonare (enfisema).

La limitazione cronica del flusso a livello delle vie aeree, caratteristica della BPCO, è generata dall'unione della bronchiolite ostruttiva delle piccole vie aeree con la distruzione parenchimale da enfisema, ognuna delle quali contribuisce in misura variabile da paziente a paziente. La riduzione della capacità delle vie aeree a rimanere pervie durante l'espirazione è data dall'infiammazione cronica, che genera un rimodellamento e un restringimento delle piccole vie aeree e dalla distruzione del parenchima polmonare, che conduce alla perdita del supporto strutturale alveolare per le piccole vie aeree e riduce il ritorno elastico del polmone.

Ne deriva che la spirometria risulta l'esame indispensabile per la diagnosi e il monitoraggio della BPCO. I parametri maggiormente utilizzati sono rappresentati dal $\mathrm{FEV}_{1}$ (volume espiratorio forzato al 1 secondo), dalla FVC (capacità vitale forzata) e dalla VC (capacità vitale). Con la progressione della malattia il $\mathrm{FEV}_{1}$ diminuisce e la riduzione del rapporto $\mathrm{FEV}_{1} / \mathrm{VC}$ (indice di Tiffeneau) è spesso il primo segno dello sviluppo della limitazione al flusso delle vie aeree. Il rapporto $\mathrm{FEV}_{1} / \mathrm{VC}$, molte volte sostituito dagli autori anglosassoni con $\mathrm{FEV}_{1} / \mathrm{FVC}$, se inferiore al 70\% permette di identificare la componente ostruttiva della limitazione funzionale respiratoria e, grazie al valore di $\mathrm{FEV}_{1}$, di classificare il paziente nei diversi stadi della malattia. Inoltre, il $\mathrm{FEV}_{1}$ presenta una minore variabilità rispetto ad altri indici dinamici delle vie aeree e può essere predetto più accuratamente in relazione all'età, al sesso e alla superficie corporea. L'esame spirometrico tuttavia necessita di particolari accorgimenti tecnici che validino la tecnica eseguita (Tabella 3).

Il test farmacodinamico con broncodilatatore si rivela particolarmente importante ai fini terapeutici. Il test di reversibilità con broncodilatatore (in genere salbutamolo: $200 \mu \mathrm{g}$, oppure il broncodilatatore $\beta 2$-agonista o anticolinergico che si intende prescrivere) permette di escludere i soggetti asmatici (ostruzione reversibile) ed è indicativo per la decisione del trattamento. Il test di reversibilità ai glucocorticoidi può rivelarsi particolarmente utile quando si voglia verificare la validità di tale approccio terapeutico e permette di identificare quei pazienti che già dopo tre mesi di trattamento con corticosteroidi per via inalatoria migliorano il FEV, e che, quindi, possono beneficiare del trattamento a lungo termine.

Tabella 3. Valutazione di una corretta procedura spirometrica

- Regolare calibrazione dello spirometro

- Piena partecipazione del paziente nell'esecuzione del test

- Assenza di irregolarità durante l'espirazione (ad es. tosse)

- Tempo di espirazione superiore a 6 sec o plateau di almeno 2 sec

- Esecuzione di almeno tre prove spirometriche

- Valutazione dei risultati comparati a standard internazionali 
Il washout dell'azoto permette di misurare il volume residuo (RV), la capacità polmonare totale (TLC) e la capacità funzionale residua (FRC). Nei BPCO, l'RV aumenta con il grado di enfisema e la TLC, inizialmente aumentata, nelle fasi terminali si riduce per la comparsa di processi fibrotici associati. Anche la FRC aumenta con la progressione della malattia, a causa della combinazione delle ridotte proprietà elastiche del polmone e la precoce chiusura delle piccole vie aeree. L'allungamento del tempo di svuotamento delle piccole vie aeree conduce alla iperinflazione dinamica polmonare e l'aumento della FRC può peggiorare la funzione e coordinazione dei muscoli inspiratori.

Dal momento che l'enfisema danneggia il letto capillare, la capacità di diffusione del monossido di carbonio al singolo respiro $\left(\mathrm{DL}_{\mathrm{CO}}\right)$ diminuisce proporzionalmente alla sua gravità. All'opposto, nei pazienti con asma e bronchite cronica nei quali non è compromessa l'integrità della membrana alveolo-capillare, la $\mathrm{DL}_{\mathrm{CO}}$ risulta nella norma. $\mathrm{La}_{\mathrm{DL}} \mathrm{CO}$ può essere utilizzata per predire la desaturazione durante l'esercizio fisico nei pazienti con BPCO: essa si verifica generalmente quando la $\mathrm{DL}_{\mathrm{CO}}$ è $<55 \%$ del predetto. Un nostro studio ha poi dimostrato che la misurazione della $\mathrm{DL}_{\mathrm{CO}}$ può essere predittiva dell'efficacia della terapia: maggiore la riduzione della $\mathrm{DL}_{\mathrm{CO}}$ minore la risposta al trattamento terapeutico con terapia di combinazione corticosteroide/broncodilatatore a lunga durata d'azione somministrati per via nalatoria.

La funzione dei muscoli respiratori, infine, può essere valutata attraverso la MIP (maximum inspiratory pressure) e MEP (maximum expiratory pressure).

\section{Modificazioni fisiopatologiche}

Le modificazioni fisiopatologiche che si sviluppano nel corso della BPCO comprendono l'ipersecrezione di muco, la disfunzione del sistema ciliare, lo squilibrio proteasi/antiproteasi, lo stress ossidativo, l'iperinflazione polmonare, l'alterazione degli scambi gassosi, l'ipertensione del circolo polmonare e il cuore polmonare.

L'ipersecrezione mucosa rappresenta il risultato del fumo di sigarette e/o dell'esposizione agli altri irritanti ed è dovuta alla stimolazione delle ghiandole mucose da parte dell'acetilcolina proveniente dalle fibre colinergiche e della sostanza P proveniente dai nervi sensoriali. È verosimile che lo stimolo più importante di secrezione mucosa sia rappresentato dall'elastasi neutrofila, proveniente dai neutrofili attivati. All'ipersecrezione mucosa segue l'iperplasia delle ghiandole sottomucose e la proliferazione delle globet cells, che avviene sotto l'influenza di fattori di crescita non ancora ben identificati.

L'epitelio ciliato dell'albero bronchiale è soggetto a metaplasia squamosa con conseguente disfunzione della clearance mucociliare favorita, in alcuni casi, dall'iperviscosità del muco che contribuisce, a sua volta, alla riduzione del flusso aereo.

La limitazione del flusso a livello delle vie aeree nel paziente con BPCO è caratteristicamente irreversibile, anche se può essere associata ad una minima componente reversibile. 
È questo un punto clinicamente importante, perché l'identificazione delle cause che portano alla irreversibilità o reversibilità dell'ostruzione bronchiale può essere particolarmente utile nell'approccio terapeutico e nella classificazione dei diversi gruppi di BPCO (Tabella 4).

La caratteristica fisiopatologica tipica della BPCO è quindi la cronica limitazione al flusso espiratorio che, nelle fasi più avanzate della malattia, si verifica anche durante il respiro a riposo. L'ostruzione è particolarmente evidente a livello delle piccole vie aeree che tendono a chiudersi durante l'espirazione, intrappolando l'aria ed aumentando, di conseguenza, il volume polmonare: FRC e RV. Durante l'esercizio fisico, nel momento in cui la richiesta ventilatoria aumenta, si osserva un progressivo intrappolamento d'aria associata ad ulteriore iperinflazione polmonare dinamica che contribuisce all'aggravamento della sintomatologia, in particolare della dispnea.

La componente irreversibile della limitazione al flusso è principalmente dovuta al rimodellamento delle piccole vie aeree, con restringimento del lume ed evoluzione fibrotica, che generano un'ostruzione con un aumento delle resistenze, cui si aggiunge la riduzione del ritorno elastico dovuto alla distruzione alveolare con ulteriore aggravamento della componente ostruttiva irreversibile. L'ostruzione delle piccole vie aeree rappresenta probabilmente il risultato di un processo infiammatorio cronico caratterizzato dall'infiltrazione neutrofila, risultato del rilascio di fattori chemiotattici quali l'interleuchina 8 (IL-8) e il leucotriene B4 $\left(\mathrm{LTB}_{4}\right)$ da parte dei macrofagi, seguita dalla secrezione di fattori fibrogenici che conducono alla fibrosi delle piccole vie aeree.

L'enfisema, che si associa alla BPCO, è conseguenza dello squilibrio fra proteasi e antiproteasi. Le proteasi sono rappresentate da: elastasi neutrofila, catepsina e metalloproteinasi della matrice extracellulare, che digeriscono l'elastina e le altre proteine strutturali della parete alveolare. Le antiproteasi proteggono contro l'attacco delle proteasi e sono rappresentate da: alfa1-antitripsina, elafina, secretory leukoprotease inhibitor (SLPI) derivato dall'epitelio nelle vie aeree, e dai quattro inibitori tessutali delle metalloproteinasi: $\mathrm{TMP}_{1-4}$, che antagonizzano gli effetti delle metalloproteinasi.

Esistono inoltre sufficienti evidenze che mostrano un aumentato stress ossidativo nella BPCO. Gli ossidanti, presenti nel fumo di sigaretta, sono liberati anche dalle cellule infiammatorie (neutrofili e macrofagi alveolari). L'aumento del carico di ossidanti nella BPCO è indicato dalla aumentata concentrazione di $\mathrm{H}_{2} \mathrm{O}_{2}$

Tabella 4. Componenti ostruttive nella BPCO

Ostruzione irreversibile

Ostruzione reversibile
Rimodellamento delle piccole vie aeree

Riduzione del ritorno elastico

Distruzione del supporto alveolare

Essudato infiammatorio

Iperproduzione di muco

Contrazione della muscolatura liscia bronchiale

Iperinflazione dinamica 
(perossido di idrogeno) nel condensato dell'aria espirata dei pazienti con BPCO, in particolare durante le riacutizzazioni. Gli ossidanti contribuiscono ad aggravare il danno della BPCO sia attraverso un decremento delle difese rappresentate dalle antiproteasi, sia attraverso l'attivazione del fattore nucleare $\mathrm{kB}$ (NF-kB) che conduce ad un'aumentata secrezione di citochine, IL-8 e tumor necrosis factoralpha (TNF- $\alpha$ ). Lo stress ossidativo conduce inoltre alla formazione di isoprostani, attraverso l'ossidazione diretta dell'acido arachidonico, che inducono ipersecrezione mucosa, essudazione plasmatica e bronco-ostruzione. L'insulto ossidativo riduce significativamente la funzionalità dell'alfa1-antitripsina, una delle proteine più importanti nella prevenzione del danno polmonare durante lo stress infiammatorio. L'ossidazione dei lipidi, infine, induce la produzione di aldeidi che interagiscono con le membrane cellulari amplificando il danno cellulare. L'ossidazione di proteine e lipidi all'interno delle cellule compromette, in ultima analisi, le normali funzioni cellulari.

Per quanto riguarda la componente reversibile dall'ostruzione nel paziente con BPCO, questa è determinata dalla presenza di essudato infiammatorio e muco a livello bronchiale, con contrazione della muscolatura liscia centrale e periferica e iperinflazione dinamica durante l'attività fisica. Tali componenti determinano un'eventuale risposta terapeutica al trattamento farmacologico.

L'evoluzione della BPCO è caratterizzata dall'alterazione degli scambi gassosi con conseguente ipossiemia arteriosa e successivamente anche da ipercapnia. Generalmente ipossiemia e ipercapnia sono frequentemente presenti quando i valori funzionali di $\mathrm{FEV}_{1}$ sono inferiori a $1 \mathrm{l}$.

Nei pazienti con BPCO affetti anche da insufficienza respiratoria cronica si può osservare un compenso metabolico associato a valori elevati di BE (eccesso basi) o bicarbonati con un $\mathrm{pH}$ ai limiti della norma.

L'ipossiemia, inizialmente presente solo sotto sforzo, nelle forme più gravi accompagna anche lo stato di riposo.

Nel considerare l'alterato rapporto ventilazione/perfusione (V/Q) nella BPCO bisogna tenere in considerazione il fatto che in questi pazienti sono presenti regioni alveolari con diversa costante di ventilazione: alveoli che richiedono tempi diversi per riempirsi, ma soprattutto per svuotarsi. Ciò determina una irregolare distribuzione della capacità ventilatoria nel soggetto BPCO.

Negli stadi più avanzati della BPCO, in seguito ad una cronica e severa ipossiemia arteriosa, spesso associata ad ipercapnia, a causa della vasocostrizione ipossica riflessa e della distruzione del letto capillare conseguente all'enfisema, può comparire un quadro di ipertensione polmonare associato alla comparsa di cuore polmonare cronico, che peggiora notevolmente la prognosi del soggetto.

Diversi elementi possono contribuire allo sviluppo di ipertensione polmonare nei pazienti con BPCO: a) l'ispessimento della parete dei vasi polmonari e la riduzione del loro calibro; b) l'ipossia, che determina per riflesso la contrazione delle fibre muscolari lisce dei vasi polmonari, con ulteriore riduzione del lume (l'ipossia infatti costituisce a livello polmonare un potente stimolo vasocostrittore); c) il danno ai sistemi di vasodilatazione dipendenti dall'endotelio, come l'al- 
terazione nella sintesi o nel rilascio di NO durante l'ipossia; d) il rilascio di peptidi ad azione prevalentemente vasocostrittrice, quali l'endotelina-1; e) la distruzione del letto capillare, che determina un ulteriore aumento della pressione necessaria per perfondere il circolo polmonare.

Molti pazienti con BPCO ipoventilano durante il sonno, aggravando il coesistente squilibrio V/Q o l'insufficienza respiratoria. Ciò provoca ulteriore ipossia e può iniziare o aggravare l'ipertensione polmonare e l'insufficienza cardiaca destra (cuore polmonare).

Il cuore polmonare cronico, determinato da patologie polmonari e associato all'aumento della pressione nel piccolo circolo e all'insufficienza cardiaca destra, può predisporre il soggetto a episodi di embolia polmonare per la tendenza alla stasi e alla trombosi del circolo venoso sistemico.

Infine, la BPCO risulta associata, negli stadi avanzati, ad effetti sistemici muscolari che determinano perdita della massa muscolare scheletrica e, quindi, peggioramento della prognosi.

In molti pazienti con BPCO la capacità di diffusione dei gas è relativamente ben preservata. Tuttavia, nel caso di marcato enfisema associato alla malattia, l'area disponibile per lo scambio dei gas è ridotta. Si osserva, di conseguenza, una riduzione della $\mathrm{DL}_{\mathrm{CO}}$ e della $\mathrm{DL}_{\mathrm{CO}} / \mathrm{VA}$.

Gli effetti dell'ostruzione statica delle vie aeree sono, a loro volta, amplificati dalla perdita del ritorno elastico polmonare conseguente alla distruzione del parenchima polmonare. Il volume a riposo del torace è determinato dal bilanciamento fra il ritorno elastico dei polmoni e della parete toracica. Ad un minor riempimento polmonare corrisponde una forza minore disponibile per bilanciare il ritorno elastico della parete toracica e, pertanto, il volume a riposo del torace è aumentato. Ciò è in parte responsabile dell'iperinflazione e dell'aumento della FRC. Inoltre, la perdita del ritorno elastico significa anche che le vie aeree collassano precocemente durante l'espirazione (ad alti volumi polmonari), aumentando la quantità di aria intrappolata nei polmoni e contribuendo ad un ulteriore incremento della FRC e del RV. L'iperinflazione dinamica si osserva nel momento in cui la gravità della limitazione al flusso è tale che la durata dell'espirazione è insufficiente a svuotare i polmoni prima della successiva fase inspiratoria. L'incremento della FRC aumenta, a sua volta, il lavoro respiratorio. Le forze di contrazione generate dai muscoli inspiratori e il carico meccanico contro il quale esse devono agire, risultano compromessi. Ne consegue che, quale risultato dell'ostruzione, il carico inspiratorio è aumentato, mentre la forza di contrazione muscolare è ridotta quale conseguenza dell'iperinflazione che altera il meccanico vantaggio dei muscoli inspiratori, riducendolo. La forza di contrazione muscolare è inoltre ridotta quale conseguenza della malnutrizione e, in alcuni casi, della fatica muscolare respiratoria.

La disfunzione dei muscoli inspiratori conduce allo sviluppo dell'ipercapnia.

Numerosi studi hanno confermato che sia la $F R C$ sia il $R V$ dei pazienti con BPCO aumentano durante l'esercizio fisico, a causa dell'aumentata iperinflazione dinamica. Non sembra invece vi siano variazioni acute della TLC. L'aumento della FRC nella BPCO è in contrasto con quanto si osserva nei soggetti normali, 
nei quali, durante l'esercizio fisico lieve, si osserva una diminuzione della FRC. In seguito ad esercizio fisico intenso, invece, la FRC aumenta anche nei soggetti normali, quale conseguenza della limitazione al flusso espiratorio che si viene a realizzare. L'aumento della FRC offre il vantaggio di mantenere il flusso espiratorio, e di conseguenza la ventilazione, quando è richiesto un aumento di quest'ultima in seguito all'esercizio fisico.

L'aumento della FRC nella BPCO è in parte imputabile a fattori statici, quali la perdita del ritorno elastico polmonare e, in parte, a fattori dinamici che si osservano alla fine dell'espirazione (rallentato svuotamento polmonare) e che conducono all'iperinflazione polmonare dinamica. L'aumento della FRC potrebbe non essere presente nel caso di malattie coesistenti, quali la fibrosi polmonare, che tendono a ridurre i volumi polmonari.

La ventilazione minuto è normale o aumentata, ma il pattern respiratorio è alterato: il volume corrente è infatti diminuito e la frequenza ventilatoria è aumentata.

Nella BPCO la TLC può essere normale o lievemente aumentata. Nei pazienti con grave enfisema la TLC è, invece, marcatamente aumentata.

Infine, alcuni pazienti con BPCO hanno difficoltà ad espellere $\mathrm{CO}_{2}$ quale risultato della fatica muscolare, del mismatch V/Q e dell'ipoventilazione alveolare, motivo per il quale aumentano la frequenza e la profondità del respiro al fine di mantenere una $\mathrm{PaCO}_{2}$ nella norma. Altri pazienti, invece, non sono in grado di mantenere un'adeguata ventilazione alveolare. In questi casi si realizza una risposta adattativa del controllo del respiro, associata ad una ridotta risposta ventilatoria alla $\mathrm{PaCO}_{2}$. Di conseguenza la $\mathrm{PaCO}_{2}$ aumenta mentre la $\mathrm{PaO}_{2}$ rappresenta un importante fattore di controllo nella regolazione del respiro. In tali pazienti che ipoventilano e sono ipossiemici, la somministrazione supplementare di ossigeno ad alte dosi li espone a rischio di narcosi da $\mathrm{CO}_{2}$ ed arresto respiratorio.

All'esame spirometrico il $\mathrm{FEV}_{1}$ è ridotto e la capacità vitale lenta $(\mathrm{VC})$ è spesso più elevata della FVC, in quanto le vie aeree collassano prematuramente durante una manovra forzata. La progressiva riduzione del $\mathrm{FEV}_{1}$, associata all'aumento della gravità della malattia nel tempo, conduce all'aggravamento della dispnea e all'instaurarsi dell'insufficienza respiratoria. I meccanismi coinvolti in tale processo sono rappresentati da: a) perdita dell'elasticità, distruzione delle pareti alveolari ed allargamento degli spazi aerei distali ai bronchioli terminali, quale risultato dell'enfisema, che conduce a perdita di supporto e chiusura delle piccole vie aeree durante l'espirazione; $b$ ) ostruzione delle piccole vie aeree quale conseguenza dell'infiammazione; c) ostruzione del lume delle piccole vie aeree da parte dell'ipersecrezione mucosa; d) contrazione del muscolo liscio; e) variazioni delle proprietà del fluido di rivestimento epiteliale del polmone che tendono ad alterare la tensione superficiale e la compliance delle vie aeree.

Il restringimento del lume delle piccole vie aeree (ostruzione) conduce all'iperinflazione dei polmoni che sono pertanto incapaci di svuotarsi. Il risultato sintomatologico di tali processi è dato dalla comparsa della dispnea da sforzo e, in seguito, anche a riposo. 
Il rapporto $\mathrm{FEV}_{1} / \mathrm{VC}$ fornisce inoltre un'indicazione accurata dell'intensità dell'ostruzione.

Nella BPCO la misurazione del $\mathrm{FEV}_{1}$ si rivela particolarmente utile nella diagnosi, specialmente se associato al test di reversibilità (test farmacodinamico con broncodilatatore). La misurazione del $\mathrm{FEV}_{1}$ consente inoltre di valutare la gravità, la prognosi e di monitorizzare la progressione della malattia e la mortalità. Il rischio di ospedalizzazione, infatti, aumenta non appena il $\mathrm{FEV}_{1}$ diminuisce.

Nelle forme gravi di BPCO è rinvenibile una varietà di alterazioni del rapporto $V / Q$. Infatti, si può osservare maggior ventilazione in alcune unità polmonari con un elevato rapporto $\mathrm{V} / \mathrm{Q}$ oppure un maggior flusso ematico che perfonde unità polmonari con basso rapporto V/Q. Le unità ad elevato rapporto V/Q rappresentano, probabilmente, regioni enfisematose caratterizzate da distruzione alveolare e perdita di vasi polmonari. Le unità polmonari con basso rapporto V/Q possono invece rappresentare aree con vie aeree parzialmente ostruite. L'assenza di shunt suggerisce che la ventilazione collaterale e che la vasocostrizione polmonare ipossica sono altamente efficienti o che l'occlusione delle vie aeree non è completa. La presenza di shunt intrapolmonari suggerisce, invece, che alcune vie aeree sono completamente ostruite, ad esempio da secrezioni bronchiali. Le anormalità del rapporto V/Q si aggravano durante le riacutizzazioni della BPCO e contribuiscono all'aumento dell'ipercapnia potenziata, a sua volta, dall'ipoventilazione alveolare. La somministrazione dell'ossigeno, pur correggendo l'ipossiemia, aggrava il rapporto V/Q che, a sua volta, contribuisce ad aumentare la $\mathrm{PCO}_{2}$ che agisce attraverso variazioni dell'attività idrogenionica e le cui conseguenze dipendono dal sottostante stato dell'equilibrio acido-base.

La massima pressione inspiratoria ed espiratoria $(M I P$ e $M E P)$ sono ridotte in molti pazienti con BPCO, a causa della perdita di forza dei muscoli respiratori. La loro misurazione è indicata nei casi in cui sia presente iperinflazione polmonare e aumento del volume residuo e si sospetti malnutrizione o miopatia steroidea, oppure quando la dispnea o l'ipercapnia non sono proporzionali alla riduzione del FEV . $^{2}$

Altro ruolo importante è rivestito dalla misurazione, in aria ambiente, dei gas ematici (emogasanalisi), soprattutto nei pazienti affetti da BPCO di grado moderato e grave. Ipossiemia e ipercapnia significative sono rare per valori di $\mathrm{FEV}_{1}>$ 1 litro. La misurazione della saturazione arteriosa dell'ossigeno (saturimetria: $\mathrm{SaO}_{2}$ ) può rappresentare un'alternativa all'emogasanalisi. Tuttavia per valori di $\mathrm{SaO}_{2} \leq 92 \%$ è sempre necessario eseguire un'emogasanalisi.

I test da sforzo respiratorio e cardiorespiratorio si rivelano, a loro volta, particolarmente utili nella valutazione dei pazienti assegnati a programmi di riabilitazione respiratoria, particolarmente quando la dispnea non è proporzionale alla riduzione del $\mathrm{FEV}_{1}$.

La vasocostrizione polmonare conseguente all'ipossia può essere causa di ipertensione polmonare e insufficienza cardiaca destra. Poiché inoltre l'ipertensione polmonare è frequentemente presente nelle forme più gravi di BPCO e la 
sua gravità è correlata alla prognosi, il ricorso a metodi non invasivi ed alternativi alla cateterizzazione del cuore destro (anche se quest'ultima rappresenta un metodo più accurato di misurazione della pressione vascolare polmonare), quali l'ecocardiografia Doppler, possono rivelarsi di qualche utilità nella valutazione prognostica.

Infine, i pazienti con BPCO possono mostrare ipossiemia e ipercapnia durante il sonno, in particolare durante la fase REM, associate ad un incremento della pressione dell'arteria polmonare e delle resistenze vascolari polmonari. L'ipossiemia notturna è a sua volta causa di policitemia e aritmie cardiache. L'esame polisonnografico è indicato nei casi in cui si sospettino apnee ostruttive del sonno (Tabella 5).

La natura eterogenea della BPCO, nella quale più organi sono coinvolti, consente di individuare pazienti che, a parità di limitazione funzionale respiratoria, presentano marcate differenze in alcuni parametri, quali costituzione fisica, tolleranza allo sforzo e performances dei gas ematici, ognuno dei quali tende a confondere la classificazione clinica.

Tabella 5. BPCO: Indagini per la diagnosi a la valutazione della gravità (vedi testo)

- $\mathrm{FEV}_{1}$

- VC O FVC

- FRV, RV, TLC (enfisema: > RV e FRC; bronchite cronica: RV e FRC possono essere nella norma)

- PEF (monitoraggio giornaliero)

- $\mathrm{DL}_{\mathrm{CO}}$ e $\mathrm{DL}_{\mathrm{CO}} / \mathrm{VA}$ (< 70\% del teorico nell'enfisema; normali nella bronchite cronica)

- Emoglobina (per correzione $\mathrm{DL}_{\mathrm{CO}}$ e valutazione policitemia)

- Test farmacodinamico con broncodilatatore (per escludere la diagnosi di asma e indirizzare le decisioni terapeutiche)

- Test farmacodinamico con broncocostrittore (per valutare il grado di iperresponsività bronchiale)

- Rx standard del torace: necessario per la valutazione iniziale e per seguire l'evoluzione clinica della malattia; permette l'esclusione di altre patologie (cancro del polmone) e di complicanze durante le riacutizzazioni (polmonite, pneumotorace); evidenzia i segni dell'enfisema polmonare, della ipertensione polmonare e del cuore polmonare cronico

- $\mathrm{SaO}_{2}$ e/o emogasanalisi

- Elettrocardiogramma (di supporto nella diagnosi dell'ipertrofia ventricolare destra, delle aritmie e degli episodi ischemici)

- Esame dell'espettorato con antibiogramma (per identificare le infezioni nel caso di mancata risposta agli antibiotici)

- Livelli di $\alpha 1$-antitripsina (enfisema nei giovani)

- Tomografia computerizzata o HRCT (valutazione bolle di enfisema, fibrosi ed eventuali bronchiectasie)

- Test da sforzo respiratorio o cardiorespiratorio

- Test del cammino (6'WT)

- MIP, MEP

- Polisonnografia 


\section{Enfisema}

L'enfisema rappresenta, frequentemente, l'evoluzione terminale della BPCO. È importante comprendere che esso è una situazione anatomopatologica polmonare, anche se spesso, e forse impropriamente, viene utilizzato come descrittivo di un quadro clinico.

L'enfisema è definibile come un aumento permanente degli spazi aerei distali ed alterazione della struttura acinare dovuti a distruzione delle pareti alveolari.

L'enfisema è la conseguenza della distruzione delle strutture fibrose, elastiche e collagene che formano la matrice del parenchima polmonare cui consegue la riduzione del ritorno elastico del polmone ed il mantenimento in stato di iperdistensione degli spazi alveolari.

L'eziopatogenesi dell'enfisema polmonare vede gli stessi fattori di rischio già descritti in precedenza per la BPCO, anche se in alcuni casi è da sottolineare la sua stretta correlazione con il deficit genetico di alfa1-antitripsina.

Questa è una rara deficienza ereditaria recessiva, presente più frequentemente nella popolazione del nord Europa. In questi soggetti si sviluppa infatti un prematuro ed accelerato sviluppo di enfisema panlobulare, sia in soggetti fumatori sia non fumatori.

La distruzione delle strutture collagene ed elastiche polmonari è dovuta fondamentalmente all'azione di enzimi proteolitici endogeni, ed in particolare dell'enzima elastasi, presente nel citoplasma delle cellule infiammatorie dell'apparato respiratorio (macrofagi alveolari e polimorfonucleati neutrofili).

Queste cellule infiammatorie sono costantemente e fisiologicamente coinvolte nei processi di difesa verso agenti provenienti dall'ambiente esterno. Il loro potenziale lesivo a livello tessutale sarebbe amplificato, se non fosse operante un meccanismo atto a limitare l'azione delle proteasi stesse endogene. Tale meccanismo inibitore è costituito prevalentemente dall'alfa1-antitripsina, una glicoproteina ad attività antiproteasica riportata per la prima volta da Laurell e Eriksson nel 1963.

Tuttavia è probabile che anche altre antiproteasi giochino un ruolo, anche se meno definito, in tale processo (es. alfa2-macroglobulina).

\section{Deficit di alfa1-antitripsina}

L'alfa1-antitripsina (alfa1-AT) prende nome dalla mobilità elettroforetica. È una glicoproteina, di peso molecolare di circa $51000 \mathrm{D}$, sintetizzata dal fegato ed immessa nel circolo ematico. L'alfa1-antitripsina ha la proprietà di legarsi avidamente agli enzimi proteolitici, che costituiscono il patrimonio enzimatico di polimorfonucleati e macrofagi, inattivando e limitando in tal modo le conseguenze della loro liberazione nell'ambiente alveolare.

Nelle situazioni in cui si osserva un alterato rapporto tra i livelli di proteasi endogene e quelli di antiproteasi, a favore delle prime, viene favorito lo sviluppo del danno enfisematoso. 
L'alfa1-AT è una proteina che presenta un polimorfismo genetico, che ne determina sia le caratteristiche qualitative, sia quelle quantitative (i livelli plasmatici). Nell'uomo ne sono state finora identificate 25 differenti varianti qualitative. Le tre varianti principali di alfa1-AT sono codificate da geni differenti e denominate con la sigla $\mathrm{Pi}$ (protease inhibitor), seguite da una lettera che ne indica la mobilità elettroforetica: $M$ (media velocità), S (slow: lenta velocità) e Z (molto lenta, come ultima lettera dell'alfabeto). Queste differenti varianti sono ereditate con modalità autosomica recessiva a penetranza variabile, e ad esse conseguono livelli plasmatici differenti di alfa1-AT.

Il genotipo più diffuso, a cui corrispondono livelli normali di alfa1-AT, è quello omozigote per il gene M (PiMM). Mentre i genotipi omozigoti PiSS e PiZZ sono abbastanza rari ed associati a livelli ridotti di proteina, rispettivamente pari al $60 \%$ e al $15 \%$ del normale.

I soggetti con genotipo omozigote $\mathrm{ZZ}$ sono circa lo $0,1 \%$ della popolazione, e presentano livelli molto bassi di alfa1-AT: inferiori a $50 \mathrm{mg} / \mathrm{dl}$. Essi sono quelli a maggior rischio di sviluppo per enfisema polmonare entro i 50 anni di età. I soggetti eterozigoti per i suddetti geni presentano livelli intermedi di alfa1-AT.

La determinazione dei livelli ematici di alfa1-AT nei differenti genotipi è correlata a caratteristiche di sintesi proteica che rendono difficile il rilascio da parte del fegato nel circolo ematico per alcuni di essi. Infatti, nei soggetti PiZZ si verifica un accumulo di alfa1-AT negli epatociti, cui può conseguire lo sviluppo di alterazioni della funzionalità epatica nel corso degli anni, tanto che più del $10 \%$ di questi individui muore per grave epatopatia.

Inoltre, l'abitudine al fumo di sigaretta in questi pazienti può accelerare la degenerazione enfisematosa. È stato osservato infatti come nei soggetti che fumano si verifica una parziale inattivazione dell' alfa1-AT ad opera di agenti ossidanti contenuti nel fumo stesso o liberati dai macrofagi o dai neutrofili.

L'enfisema dei pazienti affetti da deficit di alfa1-AT può essere definito come pneumopatia ostruttiva (PO) e si differenzia dalla BPCO in quanto quest'ultima riconosce dapprima l'instaurarsi di una bronchite cronica (BC) seguita, a sua volta, dalle alterazioni enfisematose a carico del parenchima polmonare $(\mathrm{P})$ conseguenti al danno ostruttivo $(\mathrm{O})$ che si verifica a livello delle piccole vie aeree.

Quando la BC si sovrappone al quadro tipico del deficit di alfa1-AT, si realizza una sindrome clinica simile alla BPCO caratterizzata da una maggior frequenza di riacutizzazioni batteriche e virali che caratterizza il decorso clinico di tali pazienti. L'evoluzione della sovrapposta $\mathrm{BC}$ tende inoltre ad aggravare il precedente quadro di enfisema, amplificandolo considerevolmente ed assommando gli effetti dell'enfisema centrolobulare, conseguenza della BC, a quelli dell'enfisema panlobulare, associato al deficit di alfa1-antitripsina.

\section{Anatomia patologica e fisiopatologia dell'enfisema}

È ormai chiaro che l'evoluzione naturale della bronchite cronica è rappresentata dalla BPCO con possibile componente enfisematosa. Tale degenerazione alveola- 
re è rilevata autopticamente in circa l' $80 \%$ dei soggetti con BPCO. L'aumento di volume permanente degli spazi aerei è localizzato distalmente a livello del bronchiolo terminale ed è associato alla distruzione delle pareti alveolari.

All'esame istologico le pareti alveolari si presentano sottili con ridotta vascolarizzazione e fibre elastiche frammentate.

La confluenza di alveoli vicini e la loro sovradistensione danno luogo alle caratteristiche bolle.

Le diversa distribuzione all'interno dell'acino polmonare (bronchiolo terminale respiratorio e alveoli) può determinare differenti varianti morfologiche di enfisema (Fig. 6).

L'enfisema centrolobulare o centroacinare è caratterizzato dall'interessamento delle parti centrali dell'acino, ossia dei bronchioli terminali respiratori. In questa variante gli alveoli sono generalmente indenni.

L'enfisema centrolobulare è il tipo di enfisema maggiormente correlato con il fumo di sigaretta ed è localizzato prevalentemente ai lobi superiori dei polmoni.

L'enfisema panlobulare, è associato al deficit di alfa1-antitripsina e presenta l'interessamento dell'intero acino (bronchioli respiratori e alveoli). Esso si localizza caratteristicamente alle basi polmonari e in soggetti relativamente giovani.

Una variante dei due principali tipi di enfisema è il cosiddetto enfisema parasettale o distale. Esso interessa le parti periferiche dell'acino (alveoli), mentre i bronchioli terminali respiratori risultano indenni. La localizzazione è prevalentemente in regione sottopleurica ed in prossimità di aree cicatriziali o di fibrosi. Le bolle localizzate in regione sottopleurica possono determinare episodi di pneumotorace spontaneo nei soggetti che ne sono portatori.

Da un punto di vista anatomo-clinico vengono distinti anche altri tipi di enfisema che tuttavia, pur presentando similitudini funzionali, presentano caratteristiche eziologiche differenti da quelle della BPCO. Tra questi il cosiddetto enfisema vicariante o compensatorio, che interessa un solo polmone o una regione di esso, dovuto al compenso iperdistensivo da perdita di funzione del restante tessuto polmonare o dopo resezione.

L'enfisema senile invece è caratterizzato da una degenerazione atrofica delle strutture polmonari dovuta all'età, con aumento relativo della quota di aria

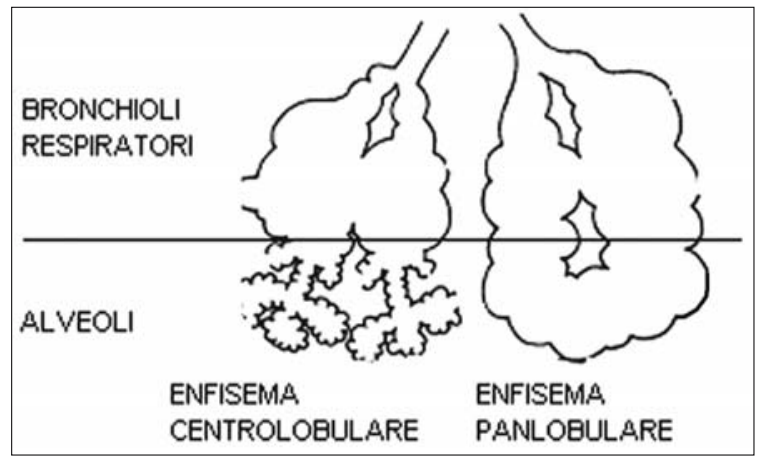

Fig. 6. Le due principali varianti anatomopatologiche di enfisema polmonare 
dovuta a iperdistensione dei bronchioli respiratori e dei dotti alveolari, mentre gli alveoli possono addirittura risultare più piccoli del normale.

In aggiunta, l'enfisema acuto da iperdistensione alveolare si realizza più frequentemente durante una grave crisi ostruttiva asmatica. In tale situazione l'aria entra dagli alveoli circostanti attraverso i pori di Kohn o i canali bronchioloalveolari di Lambert, oppure attraverso un'ostruzione parziale con meccanismo a valvola.

L'enfisema bolloso è caratterizzato dalla presenza, generalmente in sede subpleurica, di aree enfisematose di diametro superiore al centimetro. La loro rottura è una delle cause principali di pneumotorace severo.

Nell'enfisema sottocutaneo o interstiziale l'aumento del contenuto aereo interessa gli spazi aerei, come nei casi sin qui presentati, ma è dovuto ad una lacerazione parenchimale che favorisce l'ingresso dell'aria negli spazi interstiziali polmonari. Tale accumulo di aria interessa progressivamente anche il tessuto lasso mediastinico e successivamente il tessuto sottocutaneo.

Tutti questi quadri, a differenza dell'enfisema centrolobulare e panlobulare, non rientrano nella categoria etiologica della BPCO.

A livello fisiopatologico, il difetto fondamentale del polmone enfisematoso è una marcata riduzione della capacità di ritorno elastico dopo la sua distensione inspiratoria, a causa della distruzione delle fibre elastiche. La fase espiratoria, che fisiologicamente è rappresentata pressoché esclusivamente dal ritorno elastico polmonare, risulta alterata e gli alveoli tendono a restare iperdistesi.

In tale situazione i muscoli ausiliari espiratori vengono messi in azione, determinando un incremento della pressione intratoracica. Di conseguenza i bronchioli periferici (privi di cartilagine) vengono compressi e ridotti di calibro nel punto in cui la pressione intratoracica eccede la pressione dell'aria che fluisce all'interno dei bronchioli. Questo processo incrementa le resistenze delle vie aeree durante l'espirazione e rende sempre più difficoltosa l'espulsione dell'aria dagli alveoli iperdistesi.

La riduzione della superficie alveolo-capillare a causa della distruzione dei setti alveolari e della fusione di alveoli confinanti determina un'alterazione significativa degli scambi gassosi.

In particolar modo nell'enfisema centroacinare, nel quale la dilatazione interessa i bronchioli respiratori, si osserva una compromissione del trasferimento di $\mathrm{O}_{2}$ dai bronchioli terminali agli alveoli. Infatti il trasporto di $\mathrm{O}_{2}$ fino ai bronchioli terminali avviene normalmente per convenzione, mentre dai bronchioli terminali agli alveoli esso ha luogo per diffusione. Pertanto un aumento di volume (dilatazione alveolare) a questo livello determina una riduzione della ventilazione (ipoventilazione) degli alveoli.

La capacità del paziente di incrementare la ventilazione determina, come vedremo tra breve, i due tipici quadri clinici dell'enfisema (pink puffer e blue bloated), anche se non tutti i pazienti con manifestazioni sistemiche della BPCO sono sempre riconducibili ad uno dei due fenotipi. 
Quando si instaurano alterazioni della $\mathrm{PO}_{2}$ e della $\mathrm{PCO}_{2}$ nel sangue arterioso la spinta ipossica, cioè la sensibilità dei chemorecettori periferici alla ipossiemia, e la corrispondente sollecitazione ipercapnica a livello del centro midollare, stimolano nel paziente ipoventilante la ventilazione (aumento della frequenza respiratoria), per compensare i deficit di scambio.

Pertanto nei pazienti con una buona spinta ipossica, si potrà osservare un incremento della ventilazione tale da correggere l'ipossiemia arteriosa e aumentare l'eliminazione di $\mathrm{CO}_{2}$. In tal modo il soggetto evita la cianosi, al costo di un aumento del lavoro respiratorio (tachipnea). Questi pazienti vengono infatti definiti pink puffer (sbuffatore rosa). Tale quadro è caratteristico dell'enfisema panlobulare, in cui gli squilibri V/Q sono limitati.

Nel caso invece il paziente presenti una spinta ipossica debole (generalmente soggetti con enfisema centrolobulare) in cui le alterazioni V/Q sono cospicue, lo stimolo ad iperventilare dipenderà prevalentemente dall'ipercapnia. È da ricordare tuttavia che il centro midollare tende ad adattarsi alle concentrazioni elevate di $\mathrm{CO}_{2}$, pertanto lo stimolo ad iperventilare risulterà, in questi pazienti, deficitario. Inoltre l'ipossiemia cronica stimola la produzione di eritropoietina a livello renale, al fine di incrementare l'eritropoiesi. Questi meccanismi favoriscono la poliglobulia e la cianosi del paziente enfisematoso. Oltre a ciò l'ipossiemia alveolare determina, per riflesso ipossico, una vasocostrizione delle arteriole polmonari, favorendo un incremento delle resistenze vascolari del piccolo circolo, che si ripercuote sul ventricolo destro con un sovraccarico di pressione (cuore polmonare cronico). Frequentemente quindi questi pazienti presentano cianosi ed edemi declivi, e sono definiti blue bloated (blu e gonfio) (Tabella 6).

Infine, è bene ricordare che pazienti enfisematosi con ipercapnia presentano un quadro di acidosi respiratoria che può aumentare pericolosamente quando la ven-

Tabella 6. BPCO: Differenti manifestazioni di una malattia complessa. Non tutti i pazienti con manifestazioni sistemiche della BPCO sono sempre riconducibili ad uno dei due fenotipi. La natura eterogenea della BPCO, nella quale più organi sono coinvolti, consente di individuare pazienti che, a parità di limitazione funzionale respiratoria, presentano marcate differenze in alcuni parametri, quali: costituzione fisica; tolleranza allo sforzo; performances dei gas ematici, ognuno dei quali tende a confondere la classificazione clinica

\begin{tabular}{ll}
\hline Blue bloated & Pink puffer \\
\hline Tosse & Tosse \\
Espettorato & Espettorato \\
Grave enfisema & Enfisema meno grave \\
Ipossiemia & Gas ematici ai limiti nella norma \\
Ipercapnia & Dispnea a riposo \\
Ipertensione polmonare & \\
Insufficienza cardiaca destra & \\
\hline
\end{tabular}


tilazione è depressa, $\mathrm{o}$ in seguito ad una ossigenoterapia mal controllata, oppure dopo la somministrazione di farmaci sedativi che deprimono il centro del respiro.

\section{Aspetti clinici dell'enfisema}

Abbiamo già discusso come i pazienti enfisematosi si suddividono grossolanamente in due grandi categorie: il pink puffer (sbuffatore rosa) e il blue bloated (blu gonfio).

Questi due quadri clinici rappresentano gli estremi di una gamma assai vasta di presentazioni, nei quali possono prevalere le manifestazioni dell'uno o dell'altro tipo.

Anche l'esame obiettivo di un paziente enfisematoso può variare di molto in ragione del prevalere della componente bronchitica o di quella enfisematosa pura.

Potranno pertanto essere presenti, all'esame obiettivo, cianosi (labiale, sottoungueale), ippocratismo digitale, edemi declivi.

L'esame del torace, a causa della cronica iperinflazione, può evidenziare aumento dei diametri toracici, con la caratteristica deformazione "a botte", e una ridotta mobilità inspiratoria ed espiratoria.

La palpazione del torace negli enfisematosi severi può evidenziare una riduzione del fremito vocale tattile. Alla percussione invece può essere presente una iperfonesi plessica diffusa, con scomparsa dell'aia di ottusità cardiaca. La percussione rileva l'abbassamento delle basi polmonari, ipomobili, ed un allargamento delle regioni corrispondenti agli apici polmonari (campi di Krönig). Questi segni sono conferme indirette dello stato di iperinflazione presente in tali pazienti.

L'auscultazione del torace, nei pazienti prevalentemente bronchitici, evidenzierà un quadro con ronchi russanti o gementi diffusi, eventualmente associati a rantoli grossolani, mentre nei soggetti enfisematosi pink puffers, l'unico elemento rilevabile può essere rappresentato da una riduzione del murmure vescicolare su tutto l'ambito polmonare, causata dalla estesa distruzione dei setti alveolari.

Come per la bronchite cronica, non esistono alterazioni ematochimiche patognomoniche di enfisema polmonare. Solo il sospetto di deficit di alfa1-AT, in presenza di enfisema in un soggetto di età inferiore ai 50 anni, richiederà un'analisi elettroforetica delle proteine plasmatiche, con relativo dosaggio dei livelli dell'antiproteasi.

Nelle fasi avanzate della malattia, e più spesso nei pazienti blue bloated, è possibile riscontrare una poliglobulia (ematocrito $>50 \%$ e aumento dei globuli rossi). In presenza di poliglobulia il sangue diviene più viscoso e la VES tende a ridursi progressivamente. Pertanto in caso di sovrapposizione di un processo infettivo, la VES può risultare ingannevolmente nella norma.

L'emogasanalisi arteriosa riveste, nell'enfisema, un ruolo fondamentale nel valutare il grado di ipossiemia, ipercapnia, acidosi respiratoria e compenso renale.

La diagnosi di enfisema polmonare, oltre che basarsi sull'anamnesi e sui parametri clinici, richiede una conferma radiologica e soprattutto funzionale, attraverso le prove di funzionalità respiratoria (spirometria globale con valutazione del volume residuo). 
L'Rx del torace mostra in genere una caratteristica iperdiafania dei campi polmonari, dovuta alla rarefazione della trama connettivale e vascolare, soprattutto nelle regioni periferiche del polmone. Alla radiografia del torace l'aumento del volume polmonare determina l'orizzontalizzazione delle coste e l'appiattimento del diaframma, insieme all' aumento dello spazio retrosternale (Fig. 7).

Nel soggetto blue bloated prevalgono segni radiologici relativi all'impegno del cuore destro, con congestione degli ili polmonari ed eventuale allargamento dell'ombra cardiaca.

All'ECG possono essere presenti i segni caratteristici del cuore polmonare cronico, con spostamento a destra dell'asse elettrico e onda $\mathrm{P}$ di tipo polmonare.

Gli esami di funzionalità respiratoria documentano la presenza di ostruzione con riduzione del $\mathrm{FEV}_{1}$, aumento del volume residuo e del rapporto RV/TLC (indice di Motley), riduzione dei massimi flussi espiratori (MEF) e della $\mathrm{DL}_{\mathrm{CO}}$.

Alcuni studi radiologici hanno infine indicato la tomografia computerizzata ad alta risoluzione (HRCT) come un metodo non invasivo per la valutazione della gravità dell'enfisema. Tale metodica, tuttavia, riesce difficilmente a rilevare lesioni enfisematose inferiori a $0,5 \mathrm{~mm}$ di diametro. La HRCT si rivela pertanto particolarmente utile nella quantificazione morfologica dell'enfisema moderato e grave.

Il vantaggio principale della HRCT è che, oltre a fornire informazioni sulla distruzione degli alveoli polmonari, identifica zone specifiche del polmone dove la superficie alveolare è stata distrutta, consentendo di effettuare una mappa accurata della sua progressione e della localizzazione delle lesioni, particolarmente utile quando si voglia determinare l'efficacia della terapia nei pazienti con deficit di $\alpha 1$-antitripsina oppure si debba ricorrere alla riduzione chirurgica del volume polmonare.

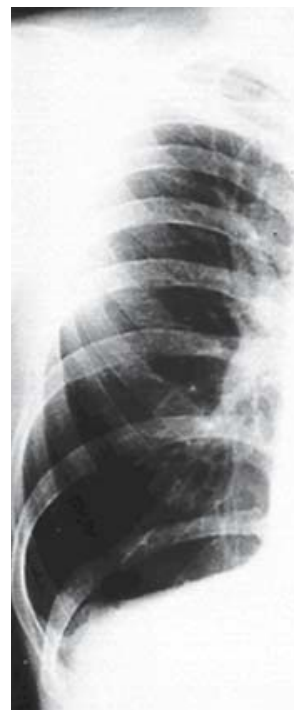

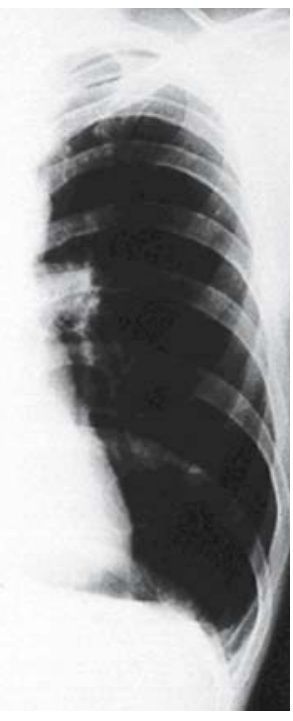

Fig. 7. Rx torace. Paziente con deficit di alfa1-antitripsina: iperinflazione poImonare bilaterale e componente bollosa distribuita prevalentemente alle basi polmonari 


\section{Diagnosi di BPCO}

L'approccio diagnostico al paziente con sospetta BPCO deve prendere in considerazione sia le caratteristiche cliniche sia quelle funzionali.

La diagnosi di BPCO dovrebbe essere considerata in tutti i soggetti con sintomi e con una storia di esposizione ai fattori di rischio, specialmente il fumo di sigaretta.

I principali sintomi della BPCO comprendono: tosse, espettorato e dispnea (Tabella 7).

Tali sintomi sono frequentemente soggetti ad episodi di riacutizzazione durante l'anno. Generalmente la tosse cronica e l'aumento dell'espettorato anticipano la comparsa dell'ostruzione delle vie aeree di alcuni anni, anche se non tutti gli individui che presentano tali sintomi svilupperanno in misura certa la malattia.

La dispnea è a carattere progressivo, aumenta nel tempo, diventa persistente e generalmente aumenta durante l'attività fisica e gli episodi di riacutizzazione. La dispnea nel soggetto BPCO è determinata dall'aumento delle resistenze delle vie aeree e dalla riduzione del ritorno elastico del polmone, che rendono l'atto respiratorio più difficoltoso (Figg. 8,9 ).

Tabella 7. Diagnosi della BPCO: sintomatologia e fattori di rischio

\section{Tosse cronica}

Espettorazione cronica

Dispnea (sotto sforzo, progressiva, persistente a riposo)

Fattori di rischio (fumo, esposizioni occupazionali)

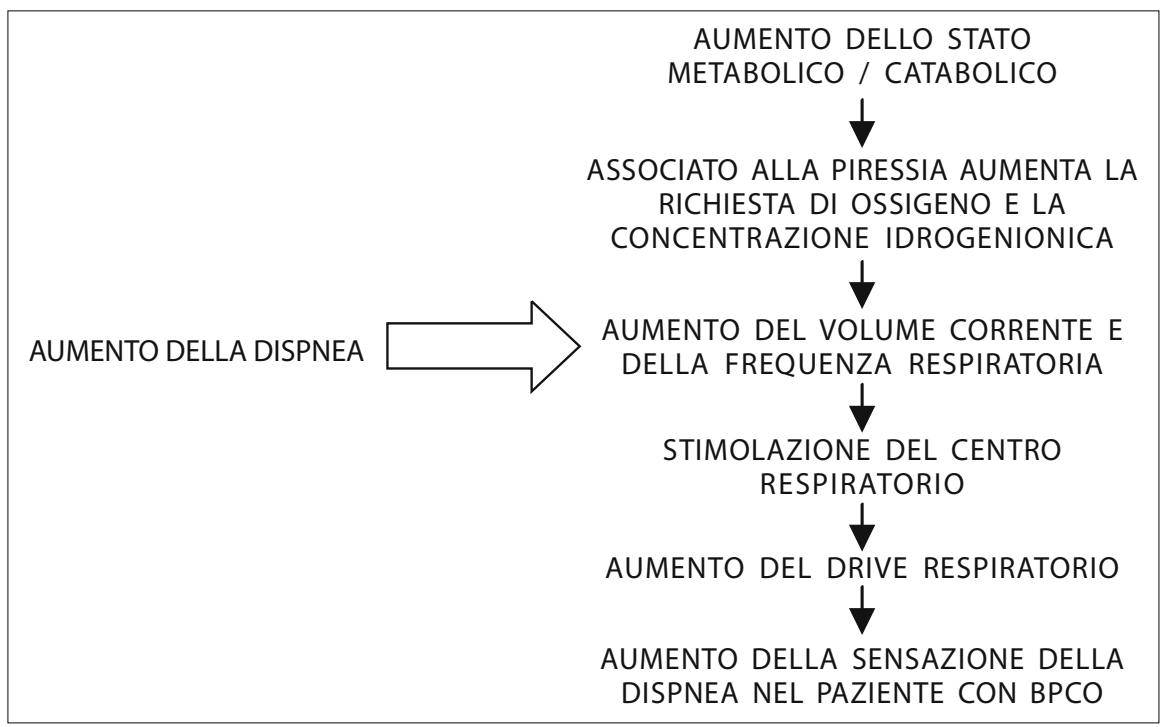

Fig. 8. Fisiopatologia dell'aumento della dispnea nella BPCO da aumento dello stato metabolico/catabolico 


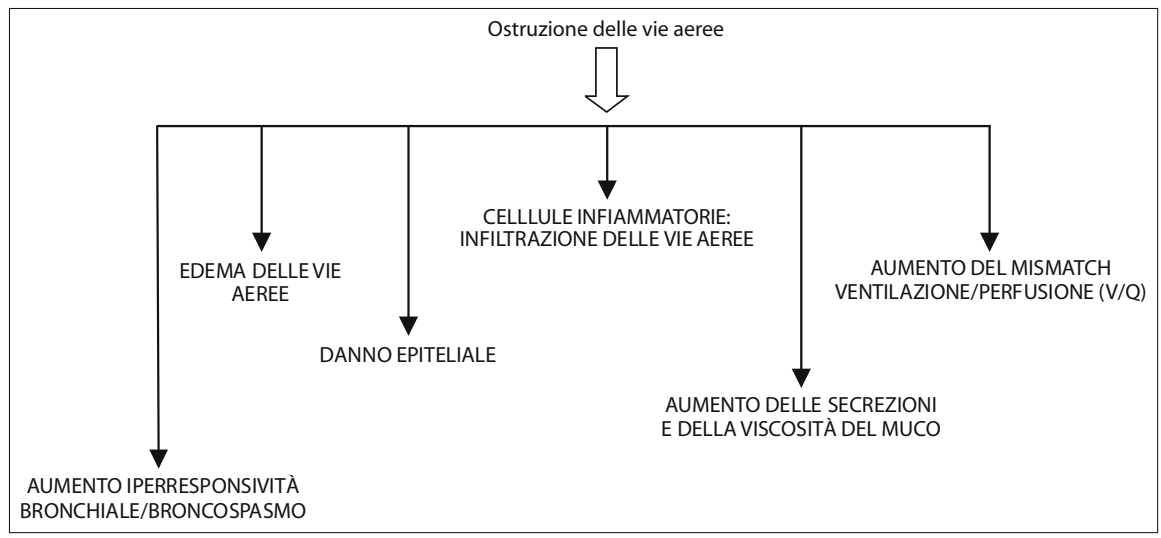

Fig 9. Fisiopatologia dell'aumento della dispnea nella BPCO imputabile ad ostruzione delle vie aeree

La dispnea è un sintomo soggettivo che può essere valutato in maniera diversa da soggetto a soggetto. A riguardo sono stati applicati diverse modalità di misura (VAS, scala di Borg, questionario MRC).

In genere, i pazienti non si rivolgono al medico fino a quando i sintomi non interferiscono con il loro stile di vita, determinando spesso una diagnosi tardiva rispetto al decorso clinico della malattia. La maggior parte dei pazienti che soffrono di BPCO si rivolgono al medico a causa della dispnea che compare negli stadi più avanzati di malattia e limita la possibilità di svolgere le normali attività quotidiane.

La tosse cronica e l'espettorato abbondante nella BPCO sono frutto della ipersecrezione mucosa e della disfunzione della clearance mucociliare. L'espettorato prodotto contiene proteine plasmatiche, cellule infiammatorie e muco.

Una dettagliata raccolta anamnestica sarà incentrata su eventuali esposizioni a fattori di rischio (fumo, inquinanti ambientali), familiarità e patologie pregresse respiratorie (asma, sinusite, poliposi nasale, broncopolmoniti), frequenza dei sintomi respiratori e riacutizzazioni, presenza di comorbidità (cardiologiche, reumatiche ecc.), trattamenti farmacologici in atto.

L'esame obiettivo deve ricercare i segni caratteristici di tale patologia (iperinflazione, basi ipomobili, cianosi), anche se la loro specificità non è elevata. All'ispezione è possibile osservare, in alcuni casi, la presenza di cianosi delle mucose, segni di iperinflazione polmonare (torace a botte, aumento del diametro toracico antero-posteriore, orizzontalizzazione costale, movimenti padarossi addominali), aumento della frequenza respiratoria, ortopnea, incremento dell'attività dei muscoli respiratori accessori, edemi periferici. Alla percussione si possono delimitare le basi polmonari e la loro ridotta mobilità. All'auscultazione è possibile riscontrare ronchi russanti, gementi e sibilanti, sibili e toni cardiaci parafonici.

La diagnosi deve essere sempre confermata dall'esame spirometrico.

La radiografia del torace può rilevare la presenza di segni di iperinflazione, come l'aumento dello spazio retrosternale, l'ispessimento della trama vascolobronchiale, l'appiattimento del diaframma e l'orizzontalizzazione costale, mentre 
la TC ad alta risoluzione (HRCT) può evidenziare la presenza di una componente enfisematosa (bolle o iperdiafania dei campi polmonari) o evoluzione regionale fibrotica degli stadi avanzati (reticolo a nido d'ape), oltre che escludere patologie associate polmonari, quali le bronchiectasie.

L'emogasanalisi riveste un ruolo fondamentale. Essa dovrebbe essere eseguita ad ogni controllo nei soggetti con grave deficit funzionale. L'emocromo ci permette di valutare la presenza di una poliglobulia associata ad uno stato di ipossiemia cronica.

In pazienti BPCO relativamente giovani ( $<45$ anni), o con familiarità, è consigliabile valutare la presenza di un deficit dell'alfal-antitripsina. Una concentrazione sierica di alfa1-antitripsina al di sotto del 15-20\% del normale è suggestiva di uno stato omozigote di deficienza.

L'esame dell'espettorato può favorire l'identificazione etiologica delle riacutizzazioni, anche se generalmente la terapia delle stesse è intrapresa empiricamente. Per l'esame dell'espettorato è indispensabile avere a disposizione un campione valido, raccolto al risveglio.

Il test del cammino di 6 minuti ( $6^{\prime} W T$ ), monitorato con saturimetro, permette di rilevare una possibile desaturazione arteriosa sotto sforzo in soggetti che a riposo presentano una saturimetria normale o ai limiti della norma.

Una valutazione di eventuali disturbi durante il sonno (apnee ostruttive) può completare la valutazione del paziente $\mathrm{BPCO}$, soprattutto se si associa obesità.

L'ecocardiografia bidimensionale, specialmente con sonda transesofagea, permette di stimare la pressione arteriosa polmonare evidenziando un eventuale quadro di ipertensione polmonare ed ipertrofia ventricolare destra.

Negli stadi più avanzati si possono osservare altri sintomi e segni associati, tra cui la perdita di peso e l'anoressia. Episodi di emoftoe sono rari nei soggetti BPCO. Tale sintomo può risultare utile nella diagnosi differenziale con altre patologie (tubercolosi, bronchiectasie). Con l'evoluzione della patologia ostruttive e la progressiva invalidità del soggetto è possibile, che alla sintomatologia di fondo, si associ un quadro depressivo.

\section{Classificazione della BPCO}

La stadiazione della BPCO è basata sul grado di ostruzione misurato all'esame spirometrico. Specifici valori di $\mathrm{FEV}_{1}$ sono stati utilizzati come valori soglia tra le varie classi. Tutti i valori di $\mathrm{FEV}_{1}$, utilizzati per la stadiazione, si riferiscono a valori ottenuti dopo una broncodilatazione con $\beta 2$-agonista short acting (salbutamolo). Tali valori comunque non presentano necessariamente una stretta correlazione con i dati clinici.

Rimane pertanto ancora da stabilire se il $\mathrm{FEV}_{1}$, da solo, sia in grado di predire la gravità della malattia oppure se, come noi invece riteniamo, sia più utile ricorrere anche ad altri parametri che con maggior precisione possono definirne il livello di gravità (FRC, $\mathrm{RV}, \mathrm{DL}_{\mathrm{CO}}, \mathrm{CI}$, volume di chiusura, ecc.). 
L'impatto della BPCO sul paziente dipende non solo dal grado di ostruzione delle vie aeree, ma anche dalla severità dei sintomi, in particolare dispnea e diminuita capacità allo sforzo.

Le varie società scientifiche internazionali di area respiratoria, utilizzando negli anni scorsi diversi valori di riferimento del $\mathrm{FEV}_{1}$ per determinare i diversi gradi di ostruzione (lieve, moderato, severo), hanno contribuito a generare una situazione di difficile inquadramento e confronto dei dati ottenuti dai vari studi sulla malattia, il che riflette la difficoltà, presente ancora oggi, di classificare una patologia come la BPCO caratterizzata da una notevole variabilità ed eterogeneità clinica.

Negli ultimi anni il progetto GOLD unitamente alle linee guida ATS-ERS sulla BPCO, ha dato luogo ad una nuova classificazione della BPCO prendendo in considerazione oltre ai parametri funzionali $\left(\mathrm{FEV}_{1}, \mathrm{FEV}_{1} / \mathrm{FVC}\right)$, anche alcune caratteristiche cliniche della malattia.

Tale classificazione suddivide i soggetti con BPCO, in base al $\mathrm{FEV}_{1}$ post-broncodilatazione, in quattro stadi (Tabella 8).

Nello stadio 0 rientrano i soggetti a rischio con bronchite cronica, con sintomi di tosse cronica e espettorazione, mentre la funzionalità polmonare risulta ancora nella norma.

Nello stadio I, BPCO lievi, i pazienti presentano una riduzione del flusso aereo e generalmente tosse cronica ed espettorato.

Nello stadio II, BPCO moderati, i parametri funzionali presentano una riduzione del flusso aereo $\left(50 \%<\mathrm{FEV}_{1}<80 \%\right.$ del teorico) insieme ad una progressione dei sintomi dispnoici. In questo stadio generalmente il paziente inizia a rivolgersi al medico per la comparsa di dispnea e tachipnea da sforzo.

Tabella 8. Classificazione GOLD-ATS/ERS 2004

\begin{tabular}{|c|c|}
\hline Stadio BPCO & Caratteristiche \\
\hline 0: a rischio (bronchite cronica) & Spirometria normale \\
\hline & Sintomi cronici (tosse, iperproduzione espettorato) \\
\hline I: lieve & $\begin{array}{l}\mathrm{FEV}_{1} / \mathrm{FVC}<70 \% \\
\mathrm{FEV}_{1} \geq 80 \% \text { del teorico } \\
\text { Con o senza sintomi cronici (tosse, iperproduzione } \\
\text { espettorato) }\end{array}$ \\
\hline II: moderata & $\begin{array}{l}\mathrm{FEV}_{1} / \mathrm{FVC}<70 \% \\
50 \leq \mathrm{FEV}_{1} \leq 80 \% \text { del teorico } \\
\text { Con o senza sintomi cronici (tosse, iperproduzione } \\
\text { espettorato) }\end{array}$ \\
\hline III: grave & $\begin{array}{l}\mathrm{FEV}_{1} / \mathrm{FVC}<70 \% \\
30 \leq \mathrm{FEV}_{1} \leq 50 \% \text { del teorico } \\
\text { Con o senza sintomi cronici (tosse, iperproduzione } \\
\text { espettorato) }\end{array}$ \\
\hline IV: molto grave & $\begin{array}{l}\mathrm{FEV}_{1} / \mathrm{FVC}<70 \% \\
\mathrm{FEV}_{1}<30 \% \text { del teorico } \\
\text { oppure } \mathrm{FEV}_{1}<50 \% \text { con insufficienza respiratoria } \\
\text { cronica }\end{array}$ \\
\hline
\end{tabular}

Classificazione su FEV1 post-broncodilatazione.

$\mathrm{FEV}_{1}=$ volume espiratorio forzato al 1 secondo, $\mathrm{FVC}=$ capacità vitale forzata; insufficienza respiratoria cronica: ipossiemia arteriosa $\left(\mathrm{PaO}_{2}>60 \mathrm{mmHg}\right)$ con o senza ipercapnia $\left(\mathrm{PaCO}_{2}>50 \mathrm{mmHg}\right)$ 
Nello stadio III, BPCO grave, i pazienti presentano un marcato peggioramento dell'ostruzione al flusso delle vie aeree, dispnea ingravescente e ripetute riacutizzazioni, che determinano un importante impatto sulla qualità di vita del soggetto.

Lo stadio $I V$, BPCO molto grave, è caratterizzato da una severa ostruzione $\left(\mathrm{FEV}_{1}<30 \%\right.$ del teorico) o dalla presenza di un quadro di insufficienza respiratoria cronica (ipossiemia: $\mathrm{PaO}_{2}<60 \mathrm{mmHg}$ con possibile ipercapnia: $\mathrm{PaCO}_{2}>50$ $\mathrm{mmHg}$ ). Inoltre il quadro di insufficienza respiratoria può determinare effetti a livello cardiaco con formazione del cuore polmonare (insufficienza cardiaca destra) e conseguenti aumento delle pressioni venose giugulari ed edemi declivi.

Anche i pazienti con un $\mathrm{FEV}_{1}>30 \%$ che presentano quadri di insufficienza respiratoria $\left(\mathrm{PaO}_{2}<60 \mathrm{mmHg} \pm\right.$ ipercapnia) o di cuore polmonare cronico rientrano nel IV stadio.

\section{Diagnosi differenziale}

Nella diagnosi differenziale della BPCO devono essere prese in considerazione tutte le patologie ostruttive che possono interessare l'albero bronchiale, come asma e bronchiectasie, le patologie infiammatorie-infettive, come broncopolmoniti, tubercolosi, bronchite cronica, bronchite acuta, polmoniti, e le ostruzioni da formazioni endobronchiali (ad es. tumori) (Tabella 9).

Tuttavia la BPCO in alcuni casi può coesistere con altre patologie, rendendo la diagnosi più impegnativa. Un classico esempio è la possibilità che le due patologie ostruttive, BPCO e asma, siano presenti nello stesso soggetto. Entrambe possono presentare la stessa sintomatologia, anche se l'asma ha carattere più variabile e discontinuo. Abbiamo osservato in precedenza come i due tipi di infiammazione siano sostenuti da cellule e mediatori differenti (eosinofili, CD4+ nell'asma; neutrofili, macrofagi e CD8+ nella BPCO) che presentano anche una differente sensibilità al trattamento corticosteroideo. La diagnosi differenziale tra le due patologie ostruttive resta pertanto di natura fisiopatologica, avendo l'asma una ostruzione reversibile al test con broncodilatatore, mentre la BPCO, pur potendo presentare una minima quota di reversibilità, è di tipo irreversibile o scarsamente reversibile.

I processi infettivi (broncopolmoniti e polmoniti), così come le stesse riacutizzazioni bronchitiche, possono essere differenziate per le caratteristiche di acuità di tali processi, per il rapido peggioramento della sintomatologia respiratoria (dispnea, tosse), nonché per la possibile presenza di febbre e modificazioni rilevanti delle caratteristiche dell'espettorato (purulenza). Nella gestione della BPCO le riacutizzazioni devono essere prontamente riconosciute e trattate adeguata-

Tabella 9. Diagnosi differenziale della BPCO

- Asma

- Bronchiectasie

- Broncopolmonite

- Bronchiolite obliterante
- Tubercolosi

- Tumori endobronchiali

- Insufficienza cardiaca congestizia 
mente, per evitare una più rapida progressione della malattia ostruttiva degenerativa. Durante le riacutizzazioni, infatti, si è osservato a livello dell'espettorato, e in alcuni studi bioptici, un aumento del numero degli eosinofili e dei neutrofili, con relativo aumento dell'azione lesiva tessutale. Fisiopatologicamente le riacutizzazioni sono caratterizzate da un peggioramento del rapporto ventilazione/perfusione, con conseguente aggravamento della ipossiemia arteriosa. In tale situazione si può riscontrare: edema, ipersecrezione, broncocostrizione, alterazione degli scambi gassosi e fatica dei muscoli respiratori.

\section{Prognosi}

La storia naturale dei soggetti con BPCO è caratterizzata da un decorso progressivo della malattia, specialmente se continua l'esposizione agli agenti eziologici responsabili. Tuttavia non tutti i soggetti presentano lo stesso andamento evolutivo.

Fletcher e Peto nel loro classico diagramma, hanno descritto i possibili andamenti che diversi gruppi di pazienti possono presentare nella progressione della patologia ostruttiva. Ognuno di essi presenta una differente inclinazione della curva di progressione, per cui il grado di evoluzione della BPCO nel corso degli anni può essere più $o$ meno rapido.

La gravità dell'ostruzione bronchiale influenza la sopravvivenza. La mortalità dei pazienti con $\mathrm{FEV}_{1}>50 \%$ è confrontabile con quella della popolazione generale. La mortalità a 10 anni risulta lievemente aumentata in quelli con $\mathrm{FEV}_{1}$ compreso fra il 35 e il 50\%. I pazienti con $\mathrm{FEV}_{1}<0,751$ ( $20 \%$ del $\left.\mathrm{FEV}_{1}\right)$ presentano una mortalità del $30 \%$ ad un anno e del $95 \%$ a 10 anni.

L'ipercapnia associata all'ipossiemia è un fattore prognostico sfavorevole. La morte dei pazienti con BPCO è generalmente causata da una complicanza medica, come l'insufficienza respiratoria acuta, gravi polmoniti, pneumotorace, aritmie cardiache o embolia polmonare.

L'educazione del paziente BPCO riveste un ruolo importante al fine di eliminare i fattori di rischio e riconoscere prontamente le riacutizzazioni e la progressione dei sintomi respiratori.

Il problema principale delle patologie infiammatorie-degenerative respiratorie è che il polmone perde le sue caratteristiche anatomo-funzionali, non rigenerandosi. Fisiologicamente la funzione polmonare raggiunge il suo massimo potenziale tra i 20 e i 30 anni e poi declina gradualmente. Se il declino naturale è accelerato da fattori esterni come il fumo di sigaretta, compaiono i sintomi respiratori e, negli stadi avanzati, l'insufficienza respiratoria.

La suscettibilità a sviluppare la malattia è diversa nei vari soggetti, per cui risulta difficile prevedere l'evoluzione a lungo termine. Abbiamo visto come il declino funzionale nei soggetti suscettibili varia da 48 a $91 \mathrm{ml} /$ anno, con picchi di $200 \mathrm{ml} /$ anno contro i $20-30 \mathrm{ml} /$ anno dei soggetti sani non fumatori.

Nei numerosi studi riportati in letteratura sulla risposta terapeutica (broncodilatatori e corticosteroidi) dei pazienti con BPCO, la percentuale di pazienti che 
migliorano i valori funzionali respiratori risulta limitata al 10-20\%. Ancora più scoraggianti sono i dati raccolti riguardanti gli effetti della terapia sulla riduzione del declino del $\mathrm{FEV}_{1}$ e sulla sopravvivenza.

\section{Terapia della BPCO}

Gli obiettivi della gestione terapeutica della BPCO comprendono la prevenzione della progressione della patologia, la riduzione dei sintomi, il miglioramento della capacità allo sforzo e della qualità di vita, la prevenzione e il trattamento delle complicanze e delle riacutizzazioni, la riduzione della mortalità e degli effetti collaterali del trattamento (Tabella 10).

Tra i provvedimenti generali smettere di fumare è estremamente importante, ed è l'unico provvedimento associato alla riduzione del declino progressivo del $\mathrm{FEV}_{1}$. Vanno inoltre evitate eventuali esposizioni ad irritanti chimici ed inquinanti aerei.

La gestione del paziente deve basarsi sul corretto inquadramento della severità dei sintomi e dei parametri funzionali. Infatti un corretto trattamento farmacologico permette di controllare la sintomatologia, migliorare la qualità di vita e ridurre la frequenza e la severità delle riacutizzazioni.

La spirometria permette di monitorare la progressione della malattia e valutare la risposta terapeutica.

I farmaci attivi sul calibro bronchiale sono rappresentati da: anticolinergici, $\beta 2$-agonisti e, in misura indiretta, le metilxantine e i cortisonici. Essi presentano meccanismi d'azione e recettori diversi e, in alcuni casi, anche sinergismo, trovando spesso un buon impiego in associazione (Tabella 11).

Tabella 10. Obiettivi del trattamento della BPCO

- Prevenire la progressione della malattia

- Migliorare i sintomi

- Prevenire e curare le riacutizzazioni

- Migliorare la tolleranza allo sforzo

- Migliorare lo stato di salute

- Prevenire e trattare le complicanze

- Ridurre la mortalità

- Minimizzare gli effetti collaterali della terapia

Tabella 11. Farmaci utilizzati nella BPCO

\section{Broncodilatatori}

Per via inalatoria: anticolinergici (tiotropio, ipratropio, ossitropio bromuro); $\beta 2$-agonisti (salbutamolo, formoterolo, salmeterolo)

Per via sistemica: metilxantine (teofillina, aminofillina)

Corticosteroidi

Per via inalatoria: beclometasone dipropionato, flunisolide, budesonide, fluticasone propionato

Per via sistemica: prednisone, metilprednisolone, deflazacort

Mucolitici

Per via inalatoria e sistemica: $\mathrm{N}$-acetilcisteina, ambroxol, carbossimetilcisteina Ossigenoterapia 
Il controllo neurorecettoriale delle vie aeree risulta determinato da differenti sezioni del sistema nervoso autonomo (sistema colinergico, adrenergico e non colinergico-non adrenergico) (Fig. 10).

I recettori muscarinici e $\beta 2$-adrenergici presentano un'azione regolatoria sul tono bronchiale con meccanismi di feedback ed autoregolazione (Tabella 12).

La scelta terapeutica va operata sulla base dell'eventuale presenza di controindicazioni e della risposta individuale a ogni singolo farmaco (Tabella 13).

I farmaci broncodilatatori (anticolinergici e $\beta 2$-agonisti) aumentano il $\mathrm{FEV}_{1}$, generalmente modificando il tono della muscolatura liscia bronchiale. Tali farmaci, migliorando il riempimento polmonare, tendono a ridurre l'ipe-

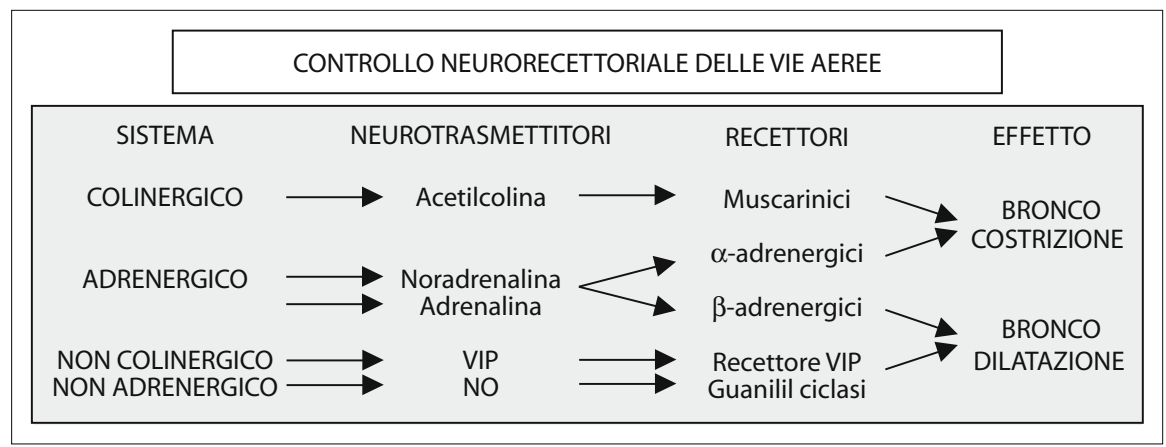

Fig. 10. Controllo neurorecettoriale delle vie aeree

Tabella 12. Controllo neurorecettoriale delle vie aeree

\begin{tabular}{|c|c|c|}
\hline Sistema nervoso & Parasimpatico & Simpatico \\
\hline Meccanismo d'azione & $\begin{array}{l}\text { Gli anticolinergici bloccano } \\
\text { l'azione dell'acetilcolina a } \\
\text { livello dei recettori colinergici, } \\
\text { causando broncodilatazione }\end{array}$ & $\begin{array}{l}\text { I } \beta 2 \text {-agonisti stimolano i } \\
\text { recettori adrenergici, } \\
\text { causando broncodilata } \\
\text { zione }\end{array}$ \\
\hline $\begin{array}{l}\text { Localizzazione } \\
\text { recettoriale }\left(^{*}\right)\end{array}$ & $\begin{array}{l}\text { Recettori colinergici presenti } \\
\text { soprattutto a livello delle } \\
\text { grandi vie aeree e delle } \\
\text { biforcazioni bronchiali }\left(^{* *}\right)\end{array}$ & $\begin{array}{l}\text { Recettori adrenergici } \\
\text { presenti prevalentemente } \\
\text { a livello delle piccole vie } \\
\text { aeree }\end{array}$ \\
\hline Variazione con l'età & $\begin{array}{l}\text { Sovraregolazione relativa } \\
\text { dei recettori colinergici } \\
\text { come conseguenza del } \\
\text { cambiamento dei recettori } \\
\text { adrenergici }\end{array}$ & $\begin{array}{l}\text { Diminuizione del numero } \\
\text { e sensibilità dei recettori } \\
\text { adrenergici }\left(^{* *}\right)\end{array}$ \\
\hline $\begin{array}{l}\text { Razionale della terapia } \\
\text { combinata di anticoli- } \\
\text { nergici e } \beta 2 \text {-agonisti }\end{array}$ & \multicolumn{2}{|c|}{$\begin{array}{l}\text { Differente meccanismo e sito d'azione complementare } \\
\text { l'uno all'altro }\left(^{*}\right)\end{array}$} \\
\hline
\end{tabular}

(*) Campbell S (1999) Arch Intern Med 159:156-160

(**) Sorkness RL, Calhoun WJ, Busse WW. Neural control of the airways and cholinergic mechanisms. In: Weiss EB, Stein M (eds) Bronchial Asthma: Mechanisms and Therapeutics. Boston, p 217

$(* * *)$ Canadian Thoracic Society Workshop Group (1992) CMAJ 147:420-28 
Tabella 13. Effetti dei farmaci broncodilatatori

\begin{tabular}{|c|c|c|}
\hline $\begin{array}{l}\beta 2 \text {-agonisti a breve } \\
\text { durata d'azione } \\
\text { (ad es. salbutamolo) }\end{array}$ & $\begin{array}{l}\beta 2 \text {-agonisti a lunga durata } \\
\text { d'azione (formoterolo, } \\
\text { salmeterolo) }\end{array}$ & $\begin{array}{l}\text { Anticolinergici (ipratropio, } \\
\text { ossitropio, tiotropio } \\
\text { bromuro) }\end{array}$ \\
\hline Aumento del FEV 1 & Aumento del $\mathrm{FEV}_{1}$ & Aumento del FEV 1 \\
\hline Riduzione della dispnea & Riduzione dei sintomi & Riduzione dei sintomi \\
\hline $\begin{array}{l}\text { Aumento della capacità } \\
\text { all'esercizio fisico }\end{array}$ & $\begin{array}{l}\text { Aumento della capacità } \\
\text { all'esercizio fisico }\end{array}$ & $\begin{array}{l}\text { Aumento della capacità } \\
\text { all'esercizio fisico }\end{array}$ \\
\hline \multirow[t]{3}{*}{$\begin{array}{l}\text { Miglioramento dello } \\
\text { stato di salute }\end{array}$} & $\begin{array}{l}\text { Miglioramento dello stato } \\
\text { di salute }\end{array}$ & $\begin{array}{l}\text { Riduzione della frequenza } \\
\text { delle riacutizzazioni }\end{array}$ \\
\hline & $\begin{array}{l}\text { Riduzione della frequenza } \\
\text { delle riacutizzazioni }\end{array}$ & $\begin{array}{l}\text { Miglioramento dello stato } \\
\text { di salute }\end{array}$ \\
\hline & & $\begin{array}{l}\text { Miglioramento della } \\
\text { qualità del sonno }\end{array}$ \\
\hline $\begin{array}{l}\text { Granulometria ideale: } \\
\text { particelle con diametro } \\
\text { aerodinamico }<2 \mu \mathrm{m}\end{array}$ & $\begin{array}{l}\text { Granulometria ideale: } \\
\text { particelle con diametro } \\
\text { aerodinamico }<2 \mu \mathrm{m}\end{array}$ & $\begin{array}{l}\text { Granulometria ideale: } \\
\text { particelle con diametro } \\
\text { aerodinamico compreso } \\
\text { fra } 3 \text { e } 5 \mu \mathrm{m}\end{array}$ \\
\hline $\begin{array}{l}\text { Sistema di erogazione dei } \\
\text { farmaci per via inalatoria: } \\
\text { - aerosol dosato } \\
\text { pressurizzato (MDI) + } \\
\text { ev. distanziatore }\end{array}$ & $\begin{array}{l}\text { Sistema di erogazione dei } \\
\text { farmaci per via inalatoria: } \\
\text { - aerosol dosato } \\
\text { pressurizzato (MDI) + } \\
\text { ev. distanziatore }\end{array}$ & $\begin{array}{l}\text { Sistema di erogazione dei } \\
\text { farmaci per via inalatoria: } \\
\text { - inalatore di polvere } \\
\text { secca (DPI) (tiotropio } \\
\text { bromuro) }\end{array}$ \\
\hline $\begin{array}{l}\text { - } \text { nebulizzatore } \\
\text { pneumatico }\end{array}$ & $\begin{array}{l}\text { - inalatore di polvere } \\
\text { secca (DPI) }\end{array}$ & $\begin{array}{l}\text { - aerosol dosato pressuriz- } \\
\text { zato (MDI) + ev. distan- } \\
\text { ziatore (ipratropio bromu- } \\
\text { ro, ossitropio bromuro) } \\
\text { - Nebulizzatore pneumati- } \\
\text { co: (ipratropio bromuro, } \\
\text { ossitropio bromuro) }\end{array}$ \\
\hline
\end{tabular}

MDI: metered dose inhaler (bombolette pressurizzate); DPI: dry powder inhaler (inalatore di polvere secca)

rinflazione dinamica a riposo e sotto sforzo. Migliorano inoltre la capacità allo sforzo fisico.

I broncodilatatori sono i principali farmaci utilizzati nella BPCO, nonostante l'ostruzione bronchiale sia irreversibile o parzialmente reversibile. Una parziale reversibilità dopo somministrazione di anticolinergici e $\beta 2$-agonisti agonisti è comunque frequente. I pazienti con maggiore risposta ai broncodilatatori mostrano un minor declino annuale di $\mathrm{FEV}_{1}$ e maggiore sopravvivenza, anche se un lungo trattamento con broncodilatatori non sembra influenzare il declino della funzione respiratoria.

La principale azione dei $\beta 2$-agonisti (salbutamolo, salmeterolo, formoterolo) è quella di favorire il rilascio del muscolo liscio bronchiale attraverso la stimolazione dei recettori $\beta 2$-adrenergici, i quali danno luogo ad un aumento dell'AMPciclico e antagonizzano l'azione dei broncocostrittori. Inoltre questi farmaci hanno anche un'azione attiva sulle ciglia vibratili dell'epitelio respiratorio, per cui possono aumentare la velocità di trasporto del muco. 
Tabella 14. Azione recettoriale muscarinica e beta-adrenergica

- Recettori muscarinici

M1: localizzati nei gangli parasimpatici, responsabili del mantenimento del tono colinergico

M2: recettori pregiunzionali localizzati sulle terminazioni nervose del muscolo bronchiale liscio, inibiscono il rilascio di ACh (autorecettori)

M3: localizzati sul muscolo bronchiale liscio, mediano l'effetto contrattile dell'ACh

- Recettori $\beta 2$ adrenergici

Recettori presinaptici posti sui neuroni postgangliari colinergici del vago inibiscono, aumentando I'AMPc, il rilascio di ACh a livello delle terminazioni nervose bronchiali, sviluppano tolleranza farmacologica e inibiscono il sistema NANC

La via di somministrazione maggiormente utilizzata per i $\beta 2$-agonisti è l'inalazione del farmaco con: a) aerosol dosato pressurizzato (MDI, metered dose inhaler) eventualmente associato ad un distanziatore; b) nebulizzatore. Fra i $\beta 2$ agonisti, quelli a lunga durata d'azione (formoterolo, salmeterolo) sono da preferire nel trattamento cronico, avendo una durata d'azione di circa 12 ore.

Gli agenti anticolinergici (ipratropio, ossitropio, tiotropio bromuro) presentano un'azione broncodilatatrice bloccando gli effetti dell'acetilcolina a livello dei recettori muscarinici M3 (Tabella 14).

L'elemento fisiopatologico dominante dell'ostruzione bronchiale nella BPCO è rappresentato dall'ipersecrezione mucosa, controllata da nervo vago, e dall'incremento del tono muscolare bronchiale, innescato da meccanismi colinergici. I broncodilatatori colinergici assumono pertanto un ruolo particolare nel trattamento della BPCO grazie alla loro caratteristica farmacologica, che si rivela in grado di ridurre il tono vagale colinergico.

Dei 5 recettori muscarinici (M1, M2, M3, M4, M5) che sono stati identificati nell'uomo, solo i sottotipi M1, M2 e M3 si rinvengono nelle vie aeree umane dove hanno dimostrato di svolgere differenti funzioni.

I recettori M1 sono localizzati a livello dei gangli parasimpatici dove facilitano la trasmissione colinergica e aumentano quindi la risposta broncocostrittiva mediata dall'acetilcolina. Il loro blocco determina una broncodilatazione e una riduzione del riflesso broncocostrittore.

I recettori M2 sono posti a livello delle terminazioni dei nervi colinergici dove agiscono con un meccansimo di feed-back inibitorio sul rilascio di acetilcolina, per cui un blocco dei recettori M2 (autorecettori) determina un aumento del rilascio di acetilcolina e un effetto di broncocostrizione.

I recettori M3 sono posti in sede post-gangliare sulla muscolatura liscia bronchiale, nonché a livello delle ghiandole mucose. Mediano la contrazione del muscolo liscio bronchiale e la secrezione ghiandolare indotta dall'acetilcolina. Il blocco dei recettori M3 determina una broncodilatazione e può contribuire a ridurre la produzione di muco (Figura 11).

I recettori M1 e M3, stimolati dall'acetilcolina, mediano l'effetto colinergico determinando una broncocostrizione, mentre i recettori M2 inviano un segnale 


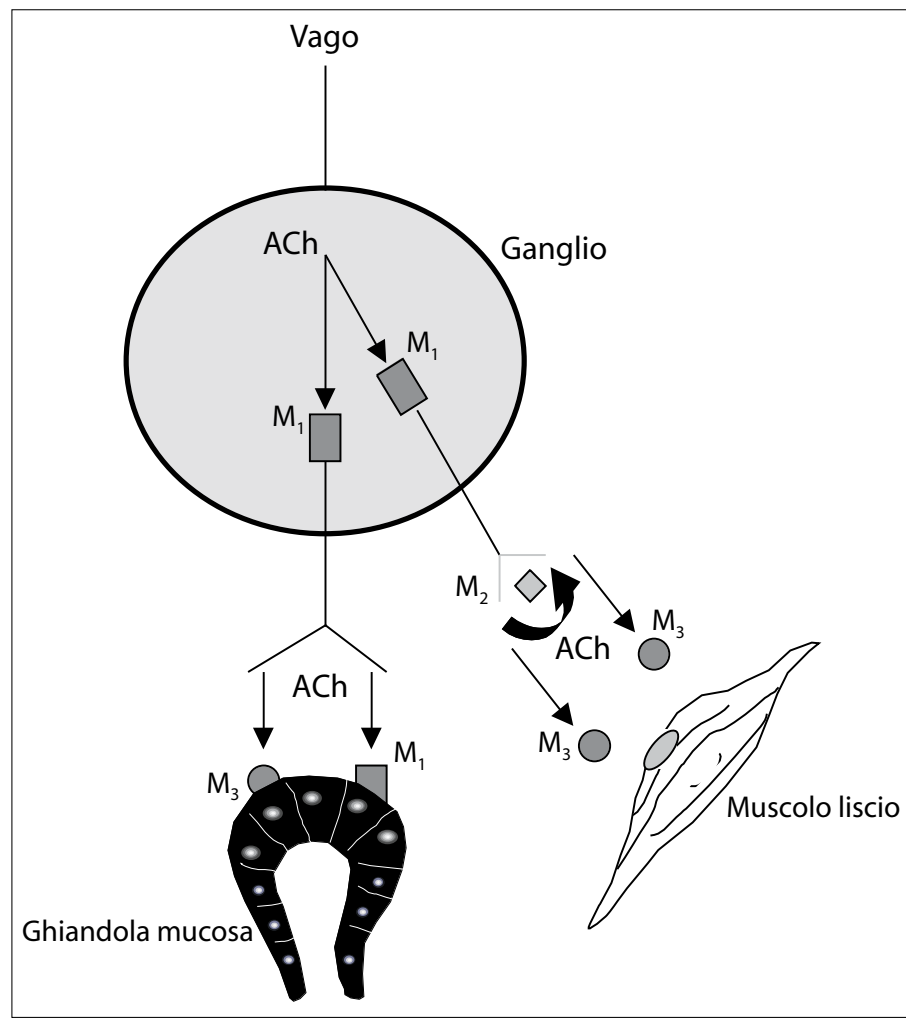

Fig. 11. Sottotipi di recettori muscarinici nelle vie aeree (M1, M2, M3). I recettori M1 facilitano la neurotrasmissione attraverso i gangli parasimpatici ed esaltano i riflessi colinergici. I recettori $\mathrm{M} 2$ agiscono come autorecettori a livello dei nervi colinergici postgangliari, inibendo il rilascio di acetilcolina con un meccanismo di feed-back negativo. I recettori M3, presenti a livello del muscolo liscio e delle ghiandole mucose delle vie aeree evocano, se stimolati, broncocostrizione e secrezione di muco

di feedback negativo alla terminazione del nervo pregiunzionale e riducono ulteriormente il rilascio di acetilcolina. Un anticolinergico ideale dovrebbe, quindi, bloccare preferibilmente i recettori M1 e M3 e mantenere la funzionalità del recettore M2 (Tabella 15).

Relativamente alla risposta broncodilatatrice nei pazienti con BPCO, molti studi hanno dimostrato che gli anticolinergici, in particolare tiotropio, sono equivalenti o superiori ai $\beta 2$-agonisti.

La mono-somministrazione per via inalatoria di tiotropio, caratterizzato da una durata d'azione di 24 ore, ha infatti dimostrato un effetto superiore, sulla dispnea nei pazienti con BPCO, rispetto a quanto osservato sia con placebo, sia con ipratropio (somministrato 4 volte al giorno), sia con salmeterolo (somministrato 2 volte al giorno).

Celli et al. (2003) hanno poi dimostrato che il tiotropio promuove una significativa riduzione dei volumi polmonari rispetto al placebo, mentre O'Donnell DE et al. e Magnussen $\mathrm{H}$ et al. (2002) hanno dimostrato che la capacità inspiratoria prima dell'inizio del test da sforzo è risultata significativamente più alta nei pazienti trattati con tiotropio e che quest'ultimo migliora significativamente la performance dello sforzo a carico costante. Il tiotropio si è inoltre rivelato in gra- 
Tabella 15. I tre sottotipi di recettori muscarinici presenti nelle vie aeree. Confronto fra tiotropio e ipratropio bromuro in termini di emivita di dissociazione del complesso farmaco-recettore per i recettori umani M1, M2 e M3 clonati ed espressi in ovociti di criceto cinese (CHO). II tiotropio bromuro rappresenta un antagonista competitivo potente e altamente specifico dell'acetilcolina. Svolge infatti un prolungato effetto farmacologico sui recettori muscarinici M1 ed M3 e una relativa breve durata d'azione sui recettori $\mathrm{M} 2$, promuovendo una prolungata broncodilatazione che dura oltre 24 ore, caratteristica che lo rende un farmaco ideale per la monosomministrazione giornaliera

\begin{tabular}{lccc}
\hline $\begin{array}{l}\text { Recettori } \\
\text { muscarinici }\end{array}$ & Funzioni & $\begin{array}{c}\text { Emivita di dissociazione } \\
\text { di tiotropio } \\
\text { dal recettore (ore) }\end{array}$ & $\begin{array}{c}\text { Emivita di dissociazione } \\
\text { di ipratropio } \\
\text { dal recettore (ore) }\end{array}$ \\
\hline M1 & $\begin{array}{c}\text { Aumentano la bronco- } \\
\text { ostruzione facilitando } \\
\text { il rilascio di ACh } \\
\text { Inibiscono il rilascio } \\
\text { di ACh }\end{array}$ & 14,6 & 0,11 \\
M2 & $\begin{array}{c}\text { Responsabili della } \\
\text { bronco-ostruzione }\end{array}$ & 34,7 & 0,035 \\
M3 & & 0,26 \\
\hline
\end{tabular}

do di migliorare la tolleranza allo sforzo e di ridurre l'iperinsufflazione prima e durante l'esercizio fisico, nonostante un aumento della ventilazione sotto sforzo. Una possibile spiegazione di tali fenomeni potrebbe risiedere nell'aumento della capacità inspiratoria associato all'inalazione di tiotropio bromuro.

Trattandosi di un anticolinergico, l'effetto collaterale più frequente con il tiotropio è rappresentato dalla secchezza delle fauci, sintomo solitamente lieve e che spesso si risolve continuando la terapia.

Mentre i farmaci anticolinergici producono un rilasciamento del muscolo liscio bronchiale attraverso i meccanismi anzidetti, i $\beta 2$-agonisti inducono una broncodilatazione attraverso la stimolazione dei recettori $\beta 2$ conducendo ad un aumento dell'AMPc (al pari di quanto si osserva con gli inibitori delle fosfodiesterasi, quali le metilxantine). I $\beta 2$-agonisti a breve durata d'azione, quale il salbutamolo, hanno un'inizio più rapido ma una più breve durata d'azione rispetto agli anticolinergici. Per tale motivo i $\beta 2$-agonisti a breve durata d'azione trovano utile collocazione nel trattamento d'urgenza del broncospasmo acuto.

I $\beta 2$-agonisti a lunga durata d'azione, salmeterolo e formoterolo, si differenziano fra loro per quanto riguarda la rapidità d'azione. Il formoterolo, infatti, è dotato di una più rapida insorgenza dell'effetto broncodilatante ( $50 \%$ della broncodilatazione massima dopo un minuto e $90 \%$ dopo un tempo massimo di dieci minuti). Il salmeterolo, invece,raggiunge il $90 \%$ della broncodilatazione massima a 60 minuti e il picco d'azione fra la seconda e la terza ora. Gli effetti collaterali dei $\beta 2$-agonisti sono rappresentati, prevalentemente da: tachicardia, aritmie, alterazioni elettrocardiografiche, ischemia miocardica, tremori, agitazione, iperglicemia, ipopotassiemia, ipofosfatemia,ipomagnesiemia e aumento degli acidi grassi liberi non esterificati. 
Un vantaggio terapeutico derivante dalle differenze di modalità d'azione e durata fra anticolinergici e $\beta 2$-agonisti è che la loro combinazione si rivela particolarmente utile nell'incrementare la broncodilatazione, rispetto alla singola classe di farmaci, e nel ridurre gli effetti collaterali, in particolare la tachifilassi presente dopo trattamento prolungato con $\beta 2$-agonisti.

Relativamente agli effetti dei broncodilatatori a lunga durata d'azione (tiotropio, salmeterolo, formoterolo) nella BPCO, è stato osservato che tali farmaci sono in grado di migliorare la funzione respiratoria e i sintomi, nonché di ridurre la frequenza delle riacutizzazioni e migliorare lo stato di salute (Tabella 16).

Le metilxantine (teofillina, aminofillina) agiscono attraverso un'inibizione della fosfodiesterasi e presentano un effetto broncodilatatore nettamente inferiore rispetto a quello degli anticolinergici e dei $\beta 2$-agonisti. Riducono la fatica della muscolatura respiratoria, promuovono la clearance mucociliare mediante un aumento della frequenza del battito ciliare ed un aumento del flusso d'acqua verso il lume bronchiale, stimolano i centri respiratori aumentando la risposta ventilatoria all'ipossiemia e all'ipercapnia, incrementano la contrazione del diaframma e dei muscoli respiratori migliorando la meccanica polmonare, svolgono effetto vasodilatante a livello del circolo polmonare riducendo la pressione arteriosa polmonare, migliorano la funzionalità ventricolare destra. Le metilxantine possono inoltre svolgere attività antinfiammatoria ed immunomodulante. La loro somministrazione, per via orale o ev, può essere particolarmente utile nei pazienti con problemi respiratori notturni. In seguito all'uso di tali farmaci, nonostante il miglioramento della sintomatologia, non si osserva nessuna modificazione spirometrica. I benefici sintomatologici sono invece piuttosto da imputare ad un riduzione del volume residuo. Purtroppo i più frequenti effetti collaterali (aritmie, tremori, agitazione) e il ristretto range terapeutico ematico, compreso tra i 5 e i $15 \mu \mathrm{g} / \mathrm{ml}$, ne limitano l'utilizzo a vantaggio degli altri broncodilatatori. Le variazioni funzionali epatiche indotte dall'età, possono inoltre indurre un elevato rischio di tossicità di tali farmaci negli anziani. Nei soggetti anziani, infine, soprattutto se cardiopatici, la teofillina, al pari dei $\beta 2$-agonisti, va utilizza-

Tabella 16. Efficacia dei broncodilatatori a lunga durata d'azione nella BPCO [modificato da:Tashkin DP, Cooper CB (2004), Chest 125:249-259]

\begin{tabular}{|c|c|c|c|c|}
\hline Farmaco & $\begin{array}{l}\text { Incremento } \\
\text { della funzione } \\
\text { respiratoria }\end{array}$ & $\begin{array}{c}\text { Riduzione } \\
\text { della } \\
\text { sintomatologia }\end{array}$ & $\begin{array}{c}\text { Riduzione della } \\
\text { frequenza delle } \\
\text { riacutizzazioni }\end{array}$ & $\begin{array}{l}\text { Miglioramento } \\
\text { dello stato } \\
\text { di salute }\end{array}$ \\
\hline Tiotropio & $\uparrow \uparrow \uparrow$ & $\uparrow \uparrow$ & $\uparrow \uparrow$ & $\uparrow \uparrow$ \\
\hline Formoterolo & $\uparrow \downarrow$ & $\uparrow \uparrow \uparrow$ & $\uparrow \uparrow \uparrow$ & $\uparrow \uparrow$ \\
\hline Salmeterolo & $\uparrow \uparrow$ & $\uparrow \uparrow \uparrow$ & $\uparrow \downarrow$ & $\uparrow \downarrow$ \\
\hline
\end{tabular}

$\uparrow \uparrow \uparrow=$ Superiore a placebo, ipratropio e salmeterolo

$\uparrow \uparrow=$ Superiore a placebo e ipratropio

$\uparrow=$ Superiore a placebo

$\uparrow \downarrow=$ Effetto ambiguo 
ta con estrema cautela considerato che a tale età gli effetti collaterali possono manifestarsi anche a concentrazioni plasmatiche comprese nel range terapeutico (Fig. 12, Tabelle 17, 18).

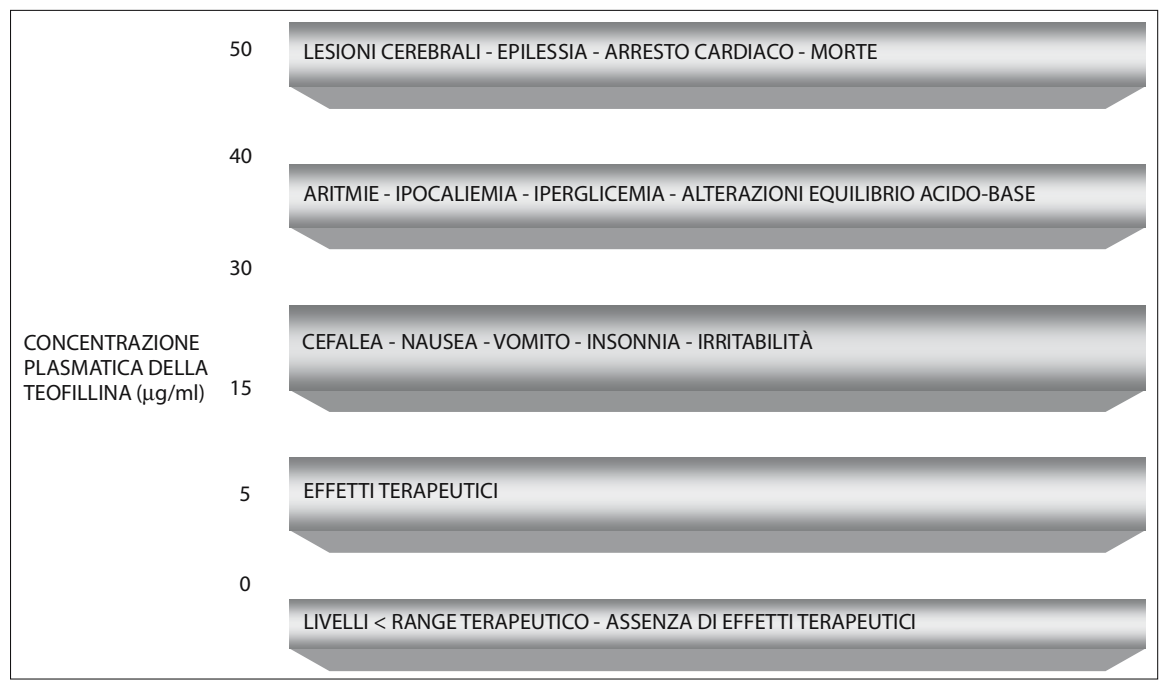

Fig 12. Effetti collaterali delle teofilline in rapporto alla concentrazione plasmatica del farmaco

Tabella 17. Teofilline

- Utilizzate come farmaci di terza scelta, in particolare quando la risposta agli anticolinergici e ai $\beta 2$-agonisti è scarsa

- Inducono frequenti effetti collaterali (nausea, aritmie, tremori, agitazione)

- Necessitano monitoraggio delle concentrazioni plasmatiche

- I livelli plasmatici risentono degli effetti di terapie concomitanti e del fumo

Tabella 18. Clearance della teofillina

Aumento della clearance (aumento della concentrazione plasmatica)

- Rifampicina, etanolo, fenobarbitone

- Fumo di tabacco e marijuana

- Età pediatrica

- Dieta (basso contenuto di carboidrati ed elevato contenuto di proteine)

- Carne alla brace

Riduzione della clearance (riduzione della concentrazione plasmatica)

- Eritromicina, ciprofloxacina, allopurinolo, cimetidina

- Malattie del fegato

- Insufficienza cardiaca congestizia

- Infezioni virali e vaccinazioni

- Polmoniti

- Dieta ad elevato contenuto di carboidrati 
L'uso dei corticosteroidi (CS) nella BPCO è stato a lungo discusso ed è controverso. Questi farmaci non danno beneficio alla maggior parte dei pazienti con BPCO stabile, visto che l'infiammazione della BPCO non risponde ai corticosteroidi, neanche se somministrati ad alte dosi (sia per via inalatoria sia per via sistemica), diversamente da quanto si verifica nell'asma. Tuttavia, nel $15-20 \%$ dei pazienti, si osserva un lieve miglioramento della funzione respiratoria dopo la loro somministrazione. Generalmente si consiglia di continuare la terapia con CS solo in quelli che presentano una risposta funzionale al trattamento steroideo dopo tre mesi. Diversi studi hanno valutato l'efficacia degli steroidi nella BPCO sul declino del $\mathrm{FEV}_{1}$ e sulla sopravvivenza, senza osservare grandi effetti a riguardo.

Un trattamento prolungato con corticosteroidi per via inalatoria può migliorare i sintomi in un gruppo definito di pazienti, aumentando la qualità di vita e riducendo il numero di riacutizzazioni, senza esplicare però alcun effetto sulla progressione della malattia e sul declino del $\mathrm{FEV}_{1}$. I CS per via inalatoria andrebbero comunque riservati a pazienti con $\mathrm{BPCO}$ con frequenti riacutizzazioni e un $\mathrm{FEV}_{1}<40 \%$.

I CS orali si sono rivelati in grado di ridurre i tempi di ricovero in ospedale e le riacutizzazioni gravi. Per contro essi non sono necessari nelle riacutizzazioni lievi. Nel caso vengano somministrati CS orali il rischio di effetti collaterali (aumento dell'appetito, ritenzione di liquidi, osteoporosi, cataratta, miopatia, diabete, ipertensione) è particolarmente elevato ed è dose e tempo-dipendente. Alcuni pazienti con concomitante asma possono mostrare una risposta ai CS. Tali pazienti, tuttavia, non sono classificabili come BPCO ma come asmatici e pertanto vanno trattati con CS per via inalatoria a lungo termine.

Recenti trials clinici hanno evidenziato come la terapia di combinazione con $\beta 2$-agonisti e corticosteroidi per via inalatoria possa migliorare la funzione respiratoria e ridurre la sintomatologia più efficacemente dei singoli farmaci. Gli effetti terapeutici più evidenti, intesi come riduzione delle riacutizzazioni e miglioramento dello stato di salute, sono stati osservati nei pazienti con un $\mathrm{FEV}_{1}<50 \%$ del predetto. Tuttavia è stata osservata una conflittualità di risultati quando le diverse terapie di combinazione (salmeterolo/fluticasone - formoterolo/budesonide) sono state comparate con i singoli farmaci, suggerendo l'esecuzione di ulteriori studi a tale proposito.

Il vaccino antinfluenzale riduce la severità delle complicanze e la mortalità dovuta ad esse di circa il 50\%. Anche il vaccino antipneumococcico, della durata di 5 anni, può risultare utile nella prevenzione delle riacutizzazioni. I derivati batterici, bactolisati immunostimolanti contenenti estratti derivati da differenti specie batteriche patogene per l'apparato respiratorio, attivano i macrofagi polmonari, aumentando il rapporto dei linfociti CD4/CD8 e modificando il livello di varie citochine polmonari.

Pazienti con espettorato particolarmente denso e viscoso possono trarre beneficio dall'uso dei mucolitici. Nella BPCO, ha dimostrato una buona azione la $\mathrm{N}$-acetilcisteina, farmaco antiossidante con azione diretta sul muco in quanto è in grado di spezzare i legami disolfurici delle mucoproteine a opera del sulfidrile libero. L'N-acetilcisteina (NAC), sembra favorire una riduzione della gra- 
vità e della frequenza delle riacutizzazioni. La NAC, grazie al suo gruppo $\mathrm{SH}$, è in grado di inattivare $\mathrm{H}_{2} \mathrm{O}_{2}$, radicale idrossilico $\left(\mathrm{OH}^{+}\right)$e acido ipocloroso $(\mathrm{HOCl})$. Inoltre la NAC è in grado di indurre la produzione cellulare di GSH mentre, a livello plasmatico, induce una riduzione dei livelli di mieloperossidasi ed elastasi. La NAC, infine, avendo mostrato di poter ridurre il progressivo declino della funzione respiratoria, può essere utilizzata nella terapia a lungo termine della BPCO.

Quanto ai farmaci ad azione indiretta (ambroxol, carbossimetilcisteina), che agiscono sulle cellule mucosecernenti regolandone capacità e qualità secretiva, questi agiscono sull'idrofilia dell'escreato, sul trasporto mucociliare e sulla produzione di surfattante alveolare.

I farmaci antitosse sono utilizzati scarsamente nella BPCO. La soppressione del meccanismo della tosse risulta infatti controproducente in questi soggetti, che necessitano di una buona capacità espettorante.

I farmaci ad azione vasodilatatrice giocano un ruolo di primo piano nel ridurre il postcarico ventricolare destro, nell'aumentare la gittata cardiaca e nel migliorare l'ossigenazione tessutale. Inoltre i diuretici possono essere utili sia in presenza di edemi periferici sia per abbassare la pressione arteriosa polmonare. Bisogna tuttavia fare attenzione all'ematocrito, già aumentato in questi soggetti, e ai disturbi dell'equilibrio acido-base e del quadro elettrolitico, per la perdita elettrolitica.

L'ossigenoterapia a lungo-termine (> 16 ore die) per pazienti con insufficienza respiratoria cronica aumenta la sopravvivenza ed ha un effetto positivo sulla pressione arteriosa polmonare, sulla policitemia, sulla capacità allo sforzo e sullo stato mentale del soggetto.

L'obiettivo dell'ossigenoterapia è di aumentare la $\mathrm{PaO}_{2}$ almeno a $60 \mathrm{mmHg}$ e raggiungere una saturazione di $\mathrm{O}_{2}$ del $90 \%$, parametri che permettono di preservare la funzione di organi vitali assicurando un adeguato apporto di ossigeno. L'ossigenoterapia va intrapresa nel paziente con grave BPCO in presenza di $\mathrm{PaO}_{2}$ $\leq 55 \mathrm{mmHg}$ e $\mathrm{SaO}_{2} \leq 88 \%$, con o senza ipercapnia. Valori più alti di $\mathrm{PaO}_{2}$ possono essere considerati come soglia se ci si trova in presenza di quadri clinici come ipertensione polmonare, edemi periferici da scompenso cardiaco congestizio, policitemia (ematocrito $>55 \%$ ).

Infine è stato osservato che la produzione di citochine pro-infiammatorie a livello polmonare può contribuire direttamente ad uno stato pro-trombotico da aumento della sintesi epatica dei fattori della coagulazione.

Inoltre, l'ipercoagulabilità, osservata nel cuore polmonare cronico, è alla base di episodi tromboembolici polmonari talora misconosciuti, che richiedono pronta diagnosi e trattamento con eparina a basso peso molecolare.

Particolare attenzione e conseguente sviluppo è stata dato negli ultimi anni a trattamenti di tipo non-farmacologico, come la riabilitazione e l'educazione del paziente.

La riabilitazione respiratoria comprende interventi di allenamento all'esercizio fisico, valutazione e controllo dello stato nutrizionale, educazione del paziente a comportamenti non a rischio. Gli obiettivi della riabilitazione sono quelli di 
ridurre i sintomi, migliorare la qualità della vita e aumentare la capacità e l'autosufficienza delle attività quotidiane.

A tutti gli stadi della malattia i pazienti possono beneficiare di programmi di allenamento allo sforzo, con miglioramento della tolleranza allo sforzo e riduzione della fatica muscolare.

In molti pazienti con forme avanzate di BPCO si osserva: un dimagrimento importante e progressivo, fino ad uno stato cachettico; un'apoptosi e disfunzione dei muscoli scheletrici; alterazioni morfologiche degli eritrociti, con conseguente alterazione del trasporto di ossigeno e quindi, condizione sommatoria di ipossia. La perdita di peso è dovuta soprattutto ad un aumento del consumo energetico a riposo da aumentato lavoro respiratorio. Particolare attenzione è stata quindi posta all'alimentazione del paziente con BPCO. In questi soggetti è preferibile instaurare una dieta iperlipidica, per la minor produzione di $\mathrm{CO}_{2}$ legata al metabolismo di queste molecole rispetto ai carboidrati e proteine. Si è osservato che una migliore alimentazione può ripristinare la forza e la resistenza muscolare respiratoria e generale. La BPCO è inoltre, di per sè, un fattore indipendente di osteoporosi, presente dal 36 al 60\% dei casi, anche quando i pazienti non sono trattati con cortisonici. Ne deriva che la profilassi (alendronato $7,5 \mathrm{mg} /$ die per sei mesi) assume particolare importanza nella profilassi delle fratture ossee. Si consideri, infatti, che le sole fratture vertebrali variano dal 49 al 63\% delle fratture totali nei pazienti con BPCO.

La ventilazione meccanica non invasiva con CPAP o BiPAP può essere utilizzata con successo nei pazienti con severa ipercapnia e durante gli episodi gravi di riacutizzazione della malattia, avendo praticamente soppiantato l'uso di stimolanti respiratori, quali il doxapram, che trovano ancora qualche utilizzazione esclusivamente nelle riacutizzazioni della BPCO, quando è presente ipercapnia e ipoventilazione e per tenere sotto controllo il paziente nelle prime $24-36$ ore, prima che la causa scatenante la riacutizzazione sia sotto controllo.

Per il trattamento dell'enfisema non esiste al giorno d'oggi alcun rimedio farmacologico efficace, anche se in tempi recenti sono state proposte terapie sperimentali basate sulla somministrazione di alfa1-AT o di agenti in grado di aumentarne la sintesi a livello epatico.

In alcuni pazienti, particolarmente pink puffers, possono essere utilizzati, con qualche successo, gli oppiacei per via inalatoria (tramite nebulizzazione) e le benzodiazepine, che riducono la sensazione della dispnea. Tuttavia, a causa della riduzione del drive ventilatorio indotto da tali farmaci, essi potrebbero rivelarsi dannosi ed andrebbero evitati, in particolare, durante le riacutizzazioni.

Più realisticamente, è conveniente agire in senso preventivo, limitando l'entità dei fattori di rischio ed intervenendo tempestivamente sulle complicanze, ad esempio infettive, che possono accelerare la progressione di una bronchite cronica verso un quadro di grave enfisema e di insufficienza respiratoria.

Negli ultimi anni molteplici sono stati gli sforzi e le risorse impegnate nella ricerca per questa così diffusa ed invalidante malattia.

L'approccio chirurgico prevede la riduzione del volume polmonare, in primo luogo dei lobi superiori, e il trapianto di polmone singolo in casi selezionati di 
grado severo. La riduzione chirurgica del volume polmonare nell'enfisema attraverso resezioni di aree relativamente non funzionali è negli ultimi anni in fase di sperimentazione. Essa consiste nell'asportare le parti più enfisematose del polmone prevalentemente ai lobi superiori, per migliorare la funzione ventilatoria. La procedura offre un modesto miglioramento del $\mathrm{FEV}_{1}$ con riduzione della TLC e miglioramento della tolleranza all'esercizio e della dispnea.

Tra le possibili proposte terapeutiche future potrebbero trovare inoltre spazio inibitori della fosfodiesterasi, antagonisti del $\mathrm{LTB}_{4}$, inibitori della lipoossigenasi, inibitori di chemochine, TNF e fattore di trascrizione NF-kB. Una più profonda conoscenza della componente genetica, unita alla promettente ricerca sulle cellule staminali, potrebbe poi indirizzare verso molecole favorenti la "ricrescita" del tessuto polmonare, come alcuni deboli dati sperimentali già hanno riportato per l'acido retinico e il fattore di crescita epatico (HGF).

I fattori che determinano la gravità della BPCO sono molteplici: severità dei sintomi e dell'ostruzione delle vie aeree, frequenza e gravità delle riacutizzazioni, presenza di patologie concomitanti o complicanze della malattia stessa, presenza di insufficienza respiratoria cronica, numero di farmaci necessari nella gestione della malattia. Tutte queste variabili individuali e inter-individuali rendono il trattamento della BPCO particolarmente indirizzato verso un approccio personalizzato.

\section{Riacutizzazioni della BPCO}

Il paziente affetto da BPCO è soggetto a periodiche riacutizzazioni, in media da 1 a 4 l'anno, durante le quali si assiste ad un peggioramento della sintomatologia di base e del quadro funzionale a volte molto importante, in alcuni casi tale da costringere il paziente al ricovero ospedaliero.

Nelle riacutizzazioni il ruolo eziopatologico delle infezioni riveste indubbiamente un momento fondamentale.

I meccanismi di difesa presenti nelle vie aeree, particolarmente se alterati o inefficaci, favoriscono la comparsa di episodi acuti ricorrenti.

Nei pazienti con patologia respiratoria cronica, inoltre, è possibile osservare a livello dell'epitelio bronchiale la presenza stabile di batteri potenzialmente patogeni per la maggior parte dei soggetti normali: colonizzazione batterica.

Questo quadro nei pazienti BPCO risulta sostenuto da un sottile equilibrio tra crescita batterica, risposta inefficace delle difese individuali, manovre invasive (cannule endobronchiali, ventilazione meccanica) e continui trattamenti antibiotici per i frequenti episodi di riacutizzazione.

La colonizzazione batterica a livello della mucosa bronchiale può favorire lo sviluppo di un circolo vizioso coinvolgente le riacutizzazioni e la progressione della malattia. L'azione lesiva sull'epitelio, la riduzione delle difese immunitarie, insieme all'incremento della flogosi e dello stress ossidativo a carico delle vie aeree, possono indurre un'accelerazione del decadimento anatomo-funzionale nella BPCO. 
In passato il potenziale ruolo delle infezioni in corso di BPCO ed il peso epidemiologico e prognostico delle riacutizzazioni si è scontrato contro la non chiara definizione di riacutizzazione.

La difficoltà di identificare una riacutizzazione risiede nel fatto che tale evento acuto è caratterizzato, clinicamente, da sintomi che coesistono e possono confondersi con i sintomi presenti nella condizione di base della BPCO (BPCO stabile). Infatti i sintomi clinici di una riacutizzazione di BPCO includono aumento della frequenza ed intensità della tosse, aumento della produzione di espettorato, presenza di espettorato purulento, sibili espiratori (a volte erroneamente attribuiti ad asma), aumento della dispnea, e varie combinazioni dei suddetti sintomi (Tabella 19). A questi possono associarsi febbre e leucocitosi e, nei casi più severi, ipossiemia ed ipercapnia. Ne deriva che i due fenotipi estremi, indicati come blue bloater e pink puffers, rappresentano ormai una classificazione obsoleta essendo raramente descritti nella pratica clinica.

Uno dei tentativi di standardizzazione clinica nella definizione di riacutizzazione della BPCO è stato quello proposto da Anthonisen. Nel 1987, Anthonisen et al. hanno individuato un criterio maggiore (Winnipeg I) e due criteri minori (Winnipeg II e Winnipeg III). Il criterio Winnipeg I, utilizzato per definire le riacutizzazioni della bronchite cronica, è dato dalla contemporanea presenza di tre segni: 1) aumento del volume dell'espettorato; 2) aumento della purulenza dell'espettorato; 3 ) aumento della dispnea. I due criteri minori definiscono la presenza di due su tre (Winnipeg II) e uno su tre (Winnipeg III) dei segni definiti dal criterio Winnipeg I (Tabella 20).

Tabella 19. Caratteristiche cliniche delle riacutizzazioni della BPCO

Peggioramento della precedente situazione stabile:

- Aumento del volume dell'espettorato

- Aumento della purulenza dell'espettorato

- Aumento della frequenza e intensità della tosse

- Aumento della dispnea

- Aumento dei sibili e dei rantoli

- Presenza di costrizione toracica

- Presenza di segni di ritenzione idrica

Tabella 20. Caratterizzazione delle riacutizzazioni della BPCO secondo Anthonisen [Anthonisen NR et al (1987) Ann Intern Med 106:196]

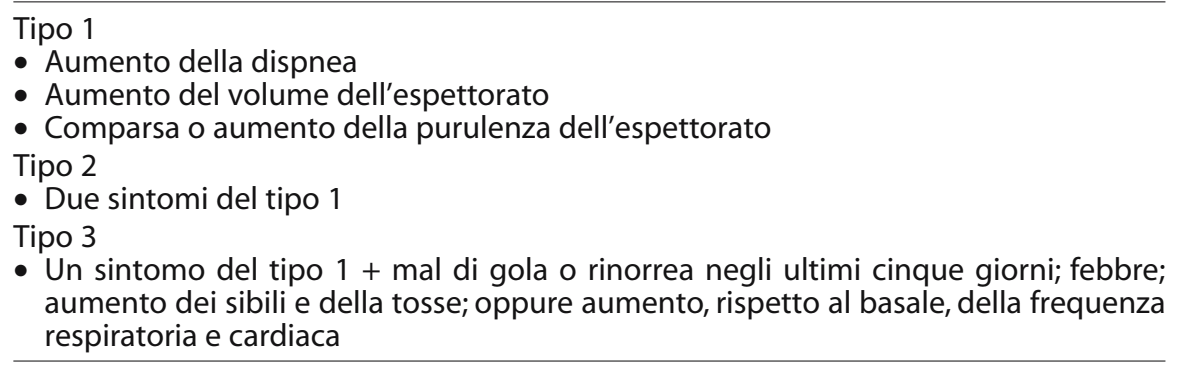


Tuttavia, in successivi lavori di altri autori sono stati evidenziati alcuni limiti della caratterizzazione di Anthonisen. Precisamente tra i criteri maggiori di Anthonisen non compare la tosse, elemento fondamentale nella definizione della bronchite cronica. La purulenza dell'espettorato e le sue variazioni sono, inoltre, difficilmente valutabili ad "occhio nudo", mentre più agevole potrebbe risultare la valutazione delle variazioni di colore dell'espettorato.

Nei paragrafi precedenti abbiamo già discusso approfonditamente i meccanismi fisiopatologici coinvolti nella BPCO. Pertanto ci limiteremo a ricordare, a proposito delle riacutizzazioni, i processi coinvolti nella genesi della sintomatologia dispnoica e della iperproduzione e modificazione delle caratteristiche dell'espettorato.

La dispnea nei pazienti BPCO in fase di riacutizzazione è dovuta prevalentemente all'aumento del grado di ostruzione bronchiale e all'aumento dello stato metabolico/catabolico (Figg. 8, 9).

Le modificazioni quantitative e qualitative dell'espettorato durante le riacutizzazioni risultano facilmente comprensibili (Fig. 13).

Anche le modificazioni dell'espettorato verso la purulenza risultano strettamente correlate all'aumento e all'attività delle cellule infiammatorie coinvolte (Fig. 14).

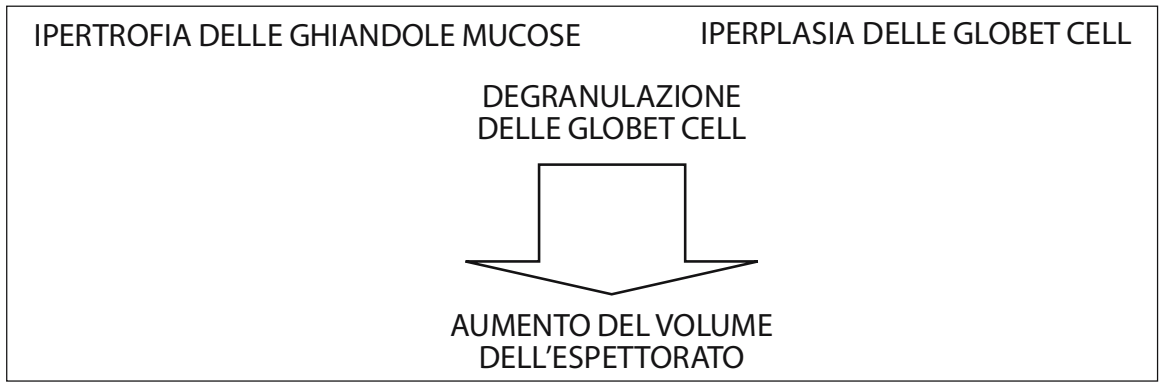

Fig. 13. Cause di aumento del volume dell'espettorato nella BPCO

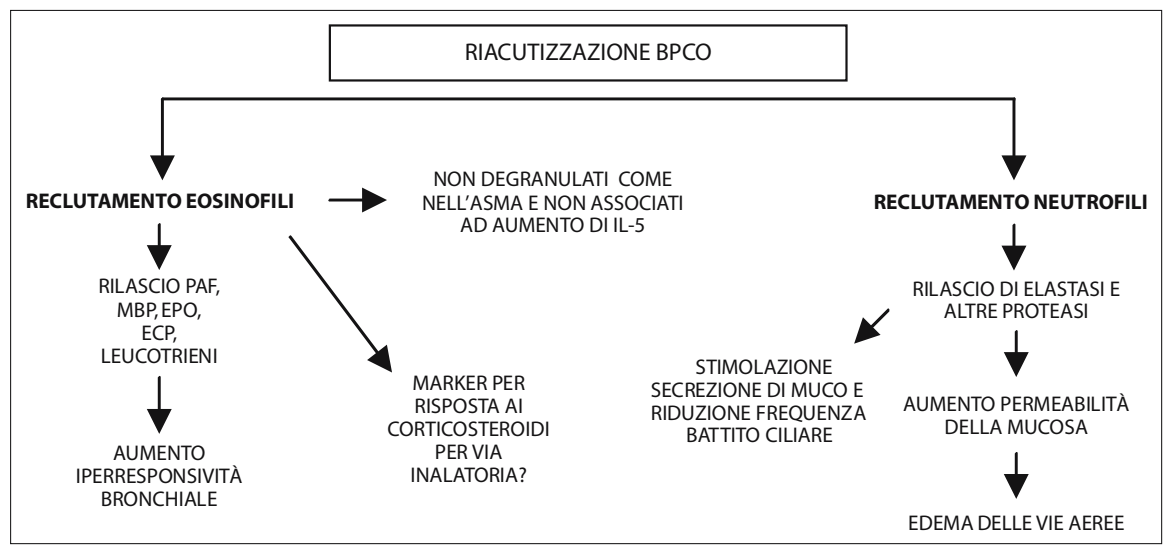

Fig. 14. Fisiopatologia della comparsa e/o aumento della purulenza dell'espettorato 


\section{Eziologia delle riacutizzazioni della BPCO}

\section{Inquinamento ambientale}

È stato ormai provato che i livelli di PM nell'aria sono associati con il rischio non solo di riacutizzazioni della $\mathrm{BPCO}$, ma anche di morte, prevalentemente per malattie respiratorie e cardiovascolari.

I dati attualmente disponibili confermano che piccole particelle, $\mathrm{PM}_{10} \mathrm{e}$ $\mathrm{PM}_{2,5}$, sospese nell'aria, rappresentano un componente altamente tossico dell'inquinamento urbano. Fra queste le particelle con diametro aerodinamico $<2,5 \mu \mathrm{m}\left(\mathrm{PM}_{2,5}\right)$ possono penetrare nelle vie aeree fino a raggiungere gli alveoli polmonari.

L'abilità dei polmoni di proteggersi nei confronti delle particelle inalate e la suscettibilità dei singoli individui nei confronti degli effetti delle particelle possono pertanto determinare la gravità degli effetti collaterali.

Ciò che ancora oggi ci chiediamo è perché tali particelle siano altamente tossiche a basse concentrazioni. Un importante meccanismo di difesa nei confronti delle particelle inalate è rappresentato dalla clearance mucociliare mentre il muco, dal canto suo, riveste un ruolo principale nella protezione delle vie aeree, soprattutto perché costituisce una ricca fonte di antiossidanti, quali mucina, acido urico, proteine (soprattutto albumina), acido ascorbico e GSH (glutatione ridotto). A livello delle grandi vie aeree le globet cells secernono muco che intrappola le particelle ivi depositate. Il muco è in seguito espulso, grazie all'azione delle cellule ciliate, attraverso l'espettorazione. Nonostante il muco possa svolgere un'azione protettiva, l'induzione dell'ipersecrezione mucosa da parte degli inquinanti ambientali $\left(\mathrm{SO}_{2}, \mathrm{PM}_{10}\right)$ può contribuire all'instaurarsi di riacutizzazioni della BPCO attraverso un aumento della resistenza al flusso delle vie aeree e lo sviluppo di tappi di muco a livello delle piccole vie aeree, caratteristica comunemente presente nei soggetti con gravi riacutizzazioni o deceduti per BPCO.

Nei pazienti affetti da BPCO si osserva, inoltre, un danno a carico delle ciglia epiteliali che, insieme all'ipersecrezione mucosa, è causa di compromissione della clearance mucociliare. L'epitelio di rivestimento delle vie aeree rappresenta una barriera agli inquinanti, ma, nello stesso tempo, un obiettivo importante per gli effetti tossici e flogistici delle particelle inalate. In seguito a tale esposizione, infatti, le cellule epiteliali rilasciano mediatori dell'infiammazione quali l'interleuchina 8 (IL-8) e le chemochine RANTES (regulated upon activation, normal T-cell expressed and secreted).

I macrofagi, presenti sulle pareti e superfici delle vie aeree possono fagocitare le particelle ma, quale risultato di ciò, rilasciano mediatori dell'infiammazione quali IL-8 e TNF (tumor necrosis factor). Nella BPCO i macrofagi risultano aumentati di numero e, di conseguenza, i livelli dei mediatori dell'infiammazione risultano aumentati nell'espettorato. Un ulteriore insulto da parte degli inquinanti inalati sarà pertanto in grado di aggravare la condizione preesistente e condurre ad una riacutizzazione della BPCO. 
L'elevato numero di particelle che si deposita a livello delle piccole vie aeree e degli alveoli, grazie ai processi di diffusione, raggiunge l'interstizio polmonare dove, non potendo più essere espulsa dai normali meccanismi di clearance, permane nelle regioni subepiteliali in prossimità dei macrofagi interstiziali, dei fibroblasti e delle cellule endoteliali oppure drena nei linfonodi, dando luogo ad una flogosi interstiziale.

L'attivazione dei neutrofili induce queste cellule a rilasciare sostanze dannose, quali le proteasi e le specie reattive dell'ossigeno (ROS). La riduzione della deformabilità dei neutrofili indotta dall'infiammazione, dal fumo di sigaretta e dalle particelle di carbonio presenti nel $\mathrm{PM}_{10}$, aumenta il sequestro di questi ultimi all'interno dei vasi polmonari, inducendo uno stress ossidativo sistemico. È stato poi osservato che particelle piccolissime, con diametro aerodinamico compreso fra 14 e $260 \mathrm{~nm}$, pur trasportando quantità trascurabili di inquinanti ambientali, hanno una tossicità rappresentata più dalla loro piccola taglia che dalla composizione chimica. I meccanismi che inducono tossicità da parte di tali particelle sono rappresentati prevalentemente dal numero di particelle inalate e dalla loro composizione chimica nonché dalla loro deposizione a livello interstiziale con conseguente stress ossidativo ed inizio dei processi che conducono all'infiammazione delle vie aeree. La ritenzione delle particelle è a sua volta agevolata dalla riduzione della clearance mucociliare, tipica della BPCO.

\section{Infezioni delle vie aeree}

Le infezioni delle vie aeree rappresentano la causa principale di riacutizzazioni nella BPCO (Fig. 15).

Altre cause meno frequenti che possono determinare un peggioramento del quadro respiratorio risultano gli episodi acuti polmonari (polmoniti, embolia) e gli scompensi di patologie concomitanti (cardiovascolari, metaboliche) (Tabella 21).

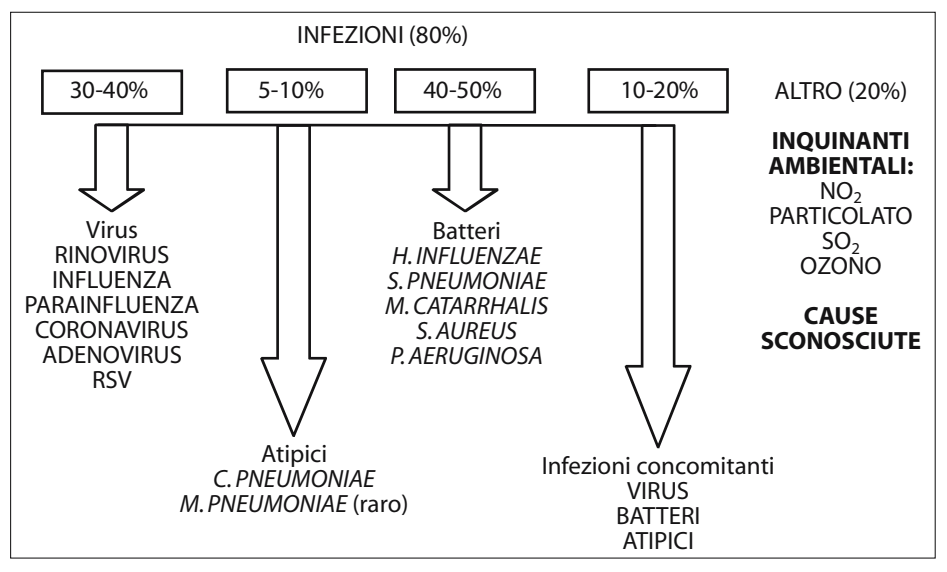

Fig. 15. Cause identificabili nelle riacutizzazioni nella BPCO 
Tabella 21. Eziologia delle riacutizzazioni della BPCO

Infezioni delle vie aeree (virali e/o batteriche)

Esposizione ad irritanti respiratori (fumo, inquinamento)

Polmonite

Embolia polmonare

Scompenso cardiocircolatorio

Aritmie cardiache

Disturbi metabolici (diabete, alterazioni elettrolitiche)

Farmaci (ipnotici, sedativi, diuretici)

Tabella 22. Prevalenza dei principali batteri nelle riacutizzazioni

\begin{tabular}{lrccc}
\hline Autore (anno) & N. ceppi & H.influenzae, \% & M. catarrhalis, \% & S. pneumoniae, \% \\
\hline Chodosh (1992) & 214 & 38 & 22 & 22 \\
Bachand (1991) & 84 & 30 & 11 & 21 \\
Lindsay (1992) & 398 & 50 & 19 & 17 \\
Anzueto (1993) & 124 & 48 & 13 & 16 \\
Ball (1995) & 84 & 52 & 13 & 17 \\
Anzueto (1998) & 673 & 28 & 18 & 7 \\
De Abate (1998) & 647 & 47 & 10 & 76,5 \\
Davies (1986) & 127 & 58,5 & 15 & 25 \\
Basran (1990) & 60 & 43,3 & 3,3 & 15 \\
Aldons (1991) & 53 & 70 & 13 & 25 \\
Neu (1993) & 84 & 46,4 & 28,6 & \\
\hline
\end{tabular}

L'eziologia infettiva delle riacutizzazioni vede i batteri coinvolti in due differenti modalità. In alcuni casi essi possono essere considerati come causa primaria della riacutizzazione, in altri possono sovrainfettare una primitiva infezione virale delle vie aeree.

Le casistiche presentate negli ultimi decenni hanno dimostrato notevoli variazioni nella prevalenza dei diversi microrganismi coinvolti (Tabella 22) nelle riacutizzazioni di BPCO.

Il ruolo dei virus nelle riacutizzazioni è rilevante (Fig. 16).

L'eziologia virale riguarda infatti circa il $30-40 \%$ dei casi (Tabella 23).

Negli ultimi anni si è osservata la comparsa di nuovi patogeni, cosiddetti emergenti, e la diminuzione della prevalenza di quelli un tempo ritenuti i principali agenti causali, soprattutto a causa dell'uso indiscriminato e non sempre giustificato degli antibiotici. Episodi ricorrenti di riacutizzazione della BPCO sono stati correlati con la comparsa di nuovi ceppi batterici di $H$. influenzae, $M$. catarrhalis, S. pneumoniae a livello delle vie aeree dei soggetti con BPCO.

A sua volta la colonizzazione batterica nei pazienti con BPCO potrebbe rappresentare un determinante importante dell'infiammazione cronica delle vie aeree. I ceppi batterici coinvolti in tali processi presentano una prevalenza caratteristica in relazione al territorio geografico in cui il paziente risiede. 


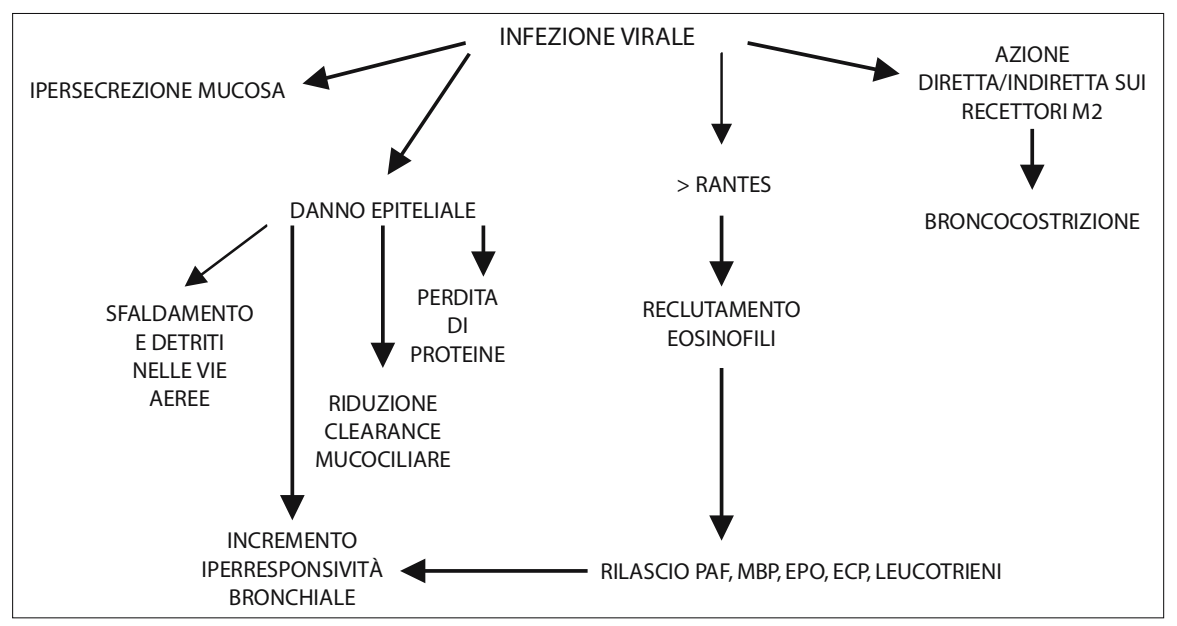

Fig. 16. Ruolo dei virus nelle riacutizzazioni della BPCO

Tabella 23. Principali agenti eziologici di riacutizzazione di BPCO

Haemophilus spp.

20-30\%

Streptococcus pneumoniae

$10-28 \%$

Moraxella catarrhalis

$10-20 \%$

Staphylococcus aureus

$3-5 \%$

Pseudomonas aeruginosa

$2-5 \%$

Mycoplasma pneumoniae

$0-3 \%$

Chlamydia pneumoniae

$4-5 \%$

Virus

$30-40 \%$

La colonizzazione batterica potrebbe rappresentare l'obiettivo di studi più approfonditi sulle riacutizzazioni della BPCO. L'esame dell'espettorato con antibiogramma potrebbe rivelarsi di valido aiuto nell'approccio terapeutico della malattia. suggerendo la somministrazione di antibiotici nel momento in cui la colonizzazione da parte dei microrganismi è talmente elevata da annunciare l'approssimarsi di una riacutizzazione della BPCO.

E stata inoltre osservata una correlazione tra il deterioramento della funzione respiratoria ed i batteri isolati in corso di riacutizzazione.

In particolare si assiste ad una più elevata incidenza di infezioni da gram+ nei soggetti con BPCO lieve, infezioni da gram-, tipo Haemophilus e Moraxella, nei soggetti con $\mathrm{FEV}_{1}$ compreso tra il 30 ed il 50\% del predetto, e una netta prevalenza di infezioni da Enterobacteriaceae e Pseudomonas nei pazienti funzionalmente più compromessi, $\mathrm{FEV}_{1}<30 \%$.

Queste osservazioni ci permettono di programmare una diversa terapia antibiotica empirica nel trattamento delle riacutizzazioni in relazione al grado di severità della BPCO. 
È bene tuttavia precisare che gli antibiotici sono raccomandati solo per le riacutizzazioni presumibilmente infettive e non a scopo preventivo. I pazienti che presentano riacutizzazioni con segni clinici di infezione bronchiale (aumento del volume e viraggio di colore dell'escreato e/o febbre) possono trarre beneficio da una terapia antibiotica. Utilizzando un farmaco adeguato in termini di attività antibatterica i risultati rispetto al placebo sono incisivi e anche più importanti nei pazienti più compromessi dal punto di vista funzionale.

Abbiamo già sottolineato come i pazienti con BPCO presentano infezioni ricorrenti che si manifestano clinicamente senza una variazione acuta della sintomatologia (colonizzazione) o con un aumento dei sintomi (riacutizzazione). La moltiplicazione, diffusione e persistenza dei batteri nel lume bronchiale ed i conseguenti danni all'epitelio, stimolano una risposta infiammatoria cronica che danneggia ulteriormente la clearance mucociliare ed il tessuto polmonare.

\section{Terapia delle riacutizzazioni della BPCO}

Nell'approccio diagnostico delle riacutizzazioni, oltre alle caratteristiche cliniche già presentate, possono risultare utili gli esami strumentali spirometrici (monitoraggio del grado di ostruzione delle vie aeree), l'emogasanalisi (ipossiemia, ipercapnia, acidosi), l'emocromo con formula leucocitaria e gli elettroliti sierici.

Riguardo all'utilità dell'esame dell'espettorato si è già discusso in precedenza. Tuttavia è bene ricordare che nella maggior parte dei casi non è possibile isolare il microrganismo responsabile e che tale strumento diagnostico può risultare particolarmente indicato in pazienti severi se si sospettano ceppi resistenti ai più comuni antibiotici (antibiogramma).

Gli esami radiologici in caso di riacutizzazione non presentano reperti caratteristici, ma possono risultare utili nella diagnosi differenziale (embolia, scompenso cardiaco) e nel sospetto di complicanze (atelettasia, pneumotorace) o interessamenti più estesi della patologia infettiva respiratoria (broncopolmoniti, polmoniti).

Ogni episodio infettivo va prontamente ed energicamente trattato. La diagnosi eziologica batterica, specifica nelle riacutizzazioni della BPCO in genere non è possibile o non conveniente per cui la terapia antibatterica, necessariamente empirica, dovrà tenere in considerazione tutti i patogeni più verosimilmente $o$ frequentemente responsabili delle riacutizzazioni della BPCO. La scelta dell'antibiotico deve essere guidata dal pattern di patogeni locali e dall'utilizzo locale di determinate classi di antibiotici (Fig. 17, Tabelle 24-28).

Gli antibiotici devono essere somministrati a dosi terapeutiche piene per un periodo di 10-14 giorni. La claritromicina e l'azitromicina richiedono, invece, periodi più brevi di somministrazione.

Bisogna tuttavia considerare che almeno un terzo delle riacutizzazioni sono associate ad infezioni virali, la maggior parte delle quali imputabili a rinovirus (raffreddore comune) e tempi prolungati di guarigione. La maggior parte dei rinovirus attaccano l'epitelio bronchiale attraverso le molecole di adesione inter- 


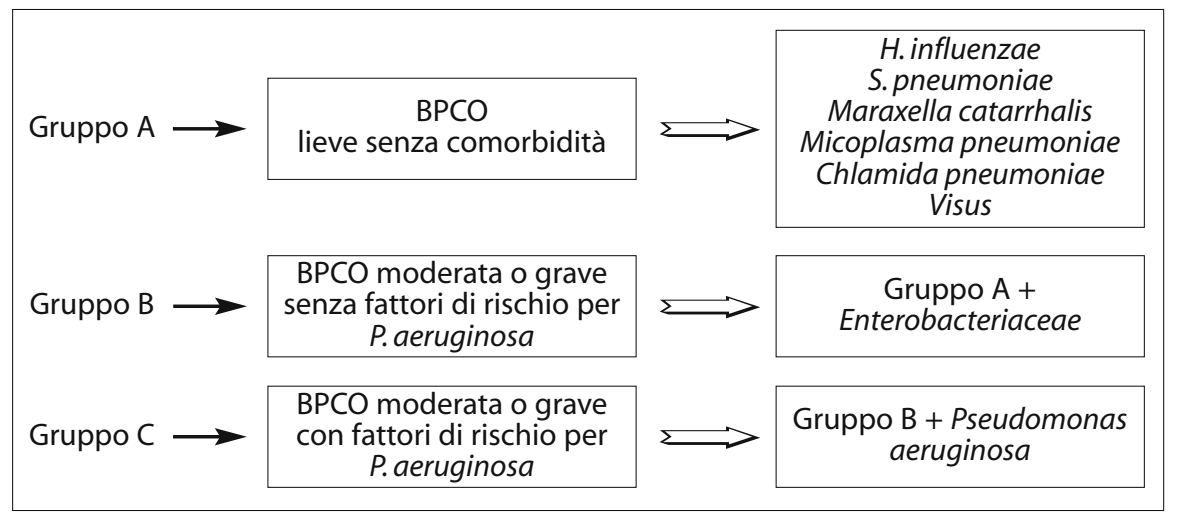

Fig. 17. Stadi BPCO e patogeni più frequentemente coinvolti

Tabella 24. Terapia delle riacutizzazioni della BPCO. Per la legenda dei diversi gruppi (A e B) vedi Tabella 28

\begin{tabular}{ll}
\hline Per os & Parenterale \\
\hline - Amoxicillina $(A)$ & - Amoxicillina $(A)$ \\
- Amoxicillina/Ac. clavulanico $(A+B)$ & - Amoxicillina/Ac. clavulanico $(A+B)$ \\
- Doxicyclina $(A)$ & - Cefalosporine seconda o terza genera- \\
- Azitromicina $(A)$ & zione $(A+B)$ \\
- Claritromicina $(A)$ & - Levofloxacina (B) \\
- Telitromicina $(A)$ & - Moxifloxacina (B) \\
- Levofloxacina (B) & \\
- Moxifloxacina (B) & \\
\hline
\end{tabular}

Tabella 25. Terapia delle riacutizzazioni della BPCO con farmaci per via orale e parenterale per il gruppo "C". Per la legenda vedi Tabella 28

- Orale: ciprofloxacina

- Parenterale: betalattamici antipseudomonas (cefepime, piperacillina/tazobactam, carbapenemici) + ciprofloxacina o + aminoglicosidi

Tabella 26. Potenziali benefici della terapia antibiotica nella BPCO

- Immediati

Riduzione dei costi di cura

Riduzione della durata dei sintomi

Evita l'ospedalizzazione

Precoce ritorno al lavoro

Evita le complicanze (polmonite)
- Lungo termine

Previene il danno progressivo delle vie aeree Prolunga l'intervallo libero

Riduce la carica batterica 
Tabella 27. Caratteristiche ideali di un antibiotico

- Rapida risoluzione dell'infezione

- Lungo intervallo tra le acuzie

- Scarsi effetti collaterali

- Non interferenze con altri farmaci

- Compliance favorevole

Tabella 28. Cause di fallimento dell'antibiotico

- Patologia cardiopolmonare

- Frequenza delle riacutizzazioni della BPCO

- Età avanzata

- Precarie condizioni generali

- Malnutrizione

- Grave compromissione della funzione respiratoria

Tabella 29. Farmaci antivirali

\begin{tabular}{|c|c|c|}
\hline Virus & Terapia & $\begin{array}{l}\text { Farmaci in corso di sperimenta- } \\
\text { zione o usati empiricamente }\end{array}$ \\
\hline Rinovirus & $/ /$ & $\begin{array}{l}\text { t-ICAMs (tremacamra, BAYz9700) } \\
\text { Pleconaril } \\
\text { AG-7088 }\end{array}$ \\
\hline Influenza A & Amantidina - Rimantidina & $/ /$ \\
\hline Influenza $A+B$ & $\begin{array}{l}\text { Zanamivir - Oseltamivir - } \\
\text { Ribavirina }\end{array}$ & RWJ-270201 \\
\hline RSV & Ribavirina - Palivizumab & $/ /$ \\
\hline Parainfluenza & // & Ribavirina \\
\hline Adenovirus & $/ /$ & Ribavirina \\
\hline Papillomavirus & $/ /$ & Alfa-interferone - Cidofovir \\
\hline Hantavirus & $/ /$ & Ribavirina \\
\hline Citomegalovirus & Ganciclovir - Immunoglobuline & Cidofovir - Foscarnet \\
\hline Herpes simplex & Acyclovir & Famciclovir - Valaciclovir \\
\hline Varicella-zoster & Acyclovir & Famciclovir - Valaciclovir \\
\hline
\end{tabular}

cellulare (ICAM-1), inducono l'espressione delle ICAM-1 e promuovono il reclutamento e l'attivazione di cellule infiammatorie. Infatti l'up-regulation delle ICAM-1 a livello della mucosa dei pazienti cn bronchite cronica suggerisce come le ICAM-1 rappresentino un target terapeutico importante nelle riacutizzazioni associate ai rinovirus. Le infezioni da rinovirus aumentano la produzione delle specie reattive dell'ossigeno ( $>$ stress ossidativo) e stimolano l'attivazione del fattore nucleare $\mathrm{Kb}$, importante nella regolazione dell'IL-8. Le infezioni da rinovirus sono inoltre associate a: 1) incremento del peptide broncocostrittore endotelina1, sia a livello delle vie aeree sia a livello sistemico; 2) incremento dei livelli di fibrinogeno plasmatico e IL-6 che stimola, a sua volta, la produzione di fibrinogeno (rischio di eventi ischemici cardio e cerebrovascolari).

I farmaci antivirali sono riportati nella Tabella 29. 
Alla terapia generalmente empirica antibiotica risulta utile associare sempre quella broncodilatatrice e corticosteroidea.

I broncodilatatori, preferibilmente anticolinergici per via inalatoria, andrebbero utilizzati da soli o in associazione ai $\beta 2$-agonisti ed, eventualmente, alle teofilline.

I CS per via inalatoria andrebbero riservati a pazienti con grave BPCO caratterizzati da frequenti riacutizzazioni e un $\mathrm{FEV}_{1}<40 \%$.

I CS orali si sono rivelati in grado di ridurre i tempi di ricovero in ospedale e le riacutizzazioni gravi. Per contro essi non sono necessari nelle riacutizzazioni lievi.

I pazienti con grave riacutizzazione della BPCO che necessitano di ospedalizzazione andranno trattati, oltre che con antibiotici (ed eventualmente antivirali) anche con CS per via sistemica ed eventualmente sottoposti a ventilazione non invasiva e/o ossigenoterapia se suggerito dal quadro emogasanalitico. Vanno inoltre trattate le patologie concomitanti, in particolare quelle cardiovascolari e il diabete, quest'ultimo causa non infrequente di gravi alterazioni dell'equilibrio elettrolitico ed acido-base.

\section{Letture consigliate}

Allegra L, Blasi F, de Bernardi B et al (2001) Antibiotic treatment and baseline severity of disease in acute exacerbations of chronic bronchitis: a re-evaluation of previously published data of a placebo-controlled randomized study. Pulm Pharmacol Ther 14:149-155

American Thoracic Society (1991) Lung function testing: selection of reference value and interpretative strategies. Am Rev Respir Dis 144:1202-1218

American Thoracic Society (1996) Standards for the diagnosis and care of patients with chronic obstructive pulmonary disease. Am J Respir Crit Care Med 152:S1-S120

Anthonisen NR, Manfreda J, Warren CP et al (1987) Antibiotic therapy in exacerbations of chronic obstructive pulmonary disease. Ann Int Med 106:196-120

Anthonisen NR, Connett JE, Kiley JP et al (1994) Effects of smoking intervention and the use of an inhaled anticholinergic bronchodilator on the rate of decline of FEV1. The Lung Health Study. JAMA 272:1497-1505

Auerbach O, Hammond EC, Garfinkel L, Benante C (1972) Relation of smoking and age to emphysema. Whole-lung section study. N Engl J Med 286:853-857

Ayres JG, Price MJ, Efthimiou J (2003) Cost-effectiveness of fluticasone propionate in the treatment of chronic obstructive pulmonary disease: a double-blind randomised, placebo-controlled trial. Respir Med 97:212-220

Baldi S, Miniati M, Bellina CR et al (2001) Relationship between extent of pulmonary emphysema by High-resolution Computed Tomography and lung elastic recoil in patients with Chronic Obstructive Pulmonary Disease. Am J Respir Crit Care Med 164:585-589

Bellia V, Pistelli R, Catalano F et al (2000) Quality control of spirometry in the elderly. The SARA Study. Am J Respir Crit Care Med 161:1094-1100

Bestall JC, Paul EA, Garrod R et al (1999) Usefulness of the Medical Research Council (MRC) dyspnoea scale as a measure of disability in patients with chronic obstructive pulmonary disease. Thorax 54:581-586

Bourbeau J (2003) Inhaled corticosteroids and survival in chronic obstructive pulmonary disease. Eur Respir J 21:202-203

Boushey HA (1999) Glucocorticoid therapy for Chronic Obstructive Pulmonary Disease. N Engl J Med 340:1990-1991 
Burge PS, Calverley PMA, Jones PW et al (2000) Randomised, double blind, placebo controlled study of fluticasone propionate in patients with moderate to severe chronic obstructive pulmonary disease: the ISOLDE trial. BMJ 320:1297-1303

Calverley PMA (2002) Medical therapy for COPD: lessons from the real world. Eur Respir J 20:797-798

Celli BR, Snider GL, Heffner J (1995) Standards for the diagnosis and care of patients with chronic obstructive pulmonary disease. Am J Respir Crit Care Med 152:S77-S121

Cosio MG, Guerassimov A (1999) Chronic Obstructive Pulmonary Disease. Inflammation of small airways and lung parenchyma. Am J Respir Crit Care Med 160:S21-S25

Cosio MG, Majo J, Cosio MG (2002) Inflammation of the airways and lung parenchyma in COPD. Role of T cells. Chest 121:160S-165S

Dorinsky PM, Reisner C, Ferguson GT et al (1999) The combination of ipratropium and albuterol optimizes pulmonary function reversibility testing in patients with COPD. Chest 115:966-971

Eller J, Ede A, Shaberg T et al (1998) Infective exacerbations of chronic bronchitis: relation between bacteriologic etiology and lung function. Chest 113:1542-1548

Epstein PE (2003) Inhaled corticosteroids and chronic obstructive pulmonary disease: are we barking up the wrong tracheobronchial tree? Ann Intern Med 138:1001-1002

Faber JP, Poller W, Olek K et al (1993) The molecular basis of alpha 1-antichymotrypsin deficiency in a heterozygote with liver and lung disease. J Hepatol 18:313-321

Finkelstein R, Fraser RS, Ghezzo H, Cosio MG (1995) Alveolar inflammation and its relation to emphysema in smokers. Am J Respir Crit Care Med 152:1666-1672

Fletcher EC, Peto R (1997) The natural history of chronic airflow obstruction. Br Med J 1:1645-1648

Global Initiative for Chronic Obstructive Lung Disease (1998) Global strategy for the diagnosis, management and prevention of chronic obstructive pulmonary disease. NHLBI/WHO workshop report

Hajiro T, Nishimura K, Tsukino M et al (2000) Stage of disease severity and factors that affect the health status of patients with chronic obstructive pulmonary disease. Respir Med 94:841-846

Harrison DJ, Cantlay AM, Rae F et al (1997) Frequency of glutathione S-transferase M1 deletion in smokers with emphysema and lung cancer. Hum Exp Toxicol 16:356-360

Highland KB, Strange C, Heffner JE (2003) Long-term effects of inhaled corticosteroids on $\mathrm{FEV}_{1}$ in patients with chronic obstructive pulmonary disease. Ann Intern Med 138:969-973

Holtzman MJ, Morton JD, Shornick LP et al (2001) Immunity, inflammation, and remodelling in the airway epithelial barrier: epithelial-viral-allergic paradigm. Physiol Rev 82:19-46

Humerfelt S, Gulsvik A, Skjaerven R et al (1993) Decline in FEV1 and airflow limitation related to occupational exposures in men of an urban community. Eur Respir J 6:1095-1103

Irwin RS, Madison JM (2003) Systemic corticosteroids for acute exacerbations of chronic obstructive pulmonary disease. N Engl J Med 348:2679-2681

Jones PW, Willits LR, Burge PS et al (2003) Disease severity and the effect of fluticasone propionate on chronic obstructive pulmonary disease exacerbations. Eur Respir J 21:68-73

Kerstjens HAM (1999) Clinical evidence stable chronic obstructive pulmonary disease. BMJ 319:495-500

Kesten S, Chapman KR (1993) Physician perceptions and management of COPD. Chest 104:254-258

Khoury MJ, Beaty TH, Newill CA et al (1986) Genetic-environmental interactions in chronic airways obstruction. Int J Epidemiol 15:65-72 
Knighton DR, Hunt TK, Scheuenstuhl H et al (1983) Oxygen tension regulates the expression of angiogenesis factor by macrophages. Science 221:1283-1285

Lane DJ, Howell JB, Giblin B (1968) Relation between airways obstruction and CO2 tension in chronic obstructive airways disease. BMJ 3:707-709

Laurell CB, Eriksson S (1963) The electrophoretic alpha-1 globulin pattern of serum in alpha-1 antitrypsin deficiency. Scand J Clin Lab Invest 15:132-140

Leuenberger P, Schwartz J, Ackermann-Liebrich U et al (1994) Passive smoking exposure in adults and chronic respiratory symptoms (SAPALDIA Study). Swiss Study on Air Pollution and Lung Diseases in Adults, SAPALDIA Team. Am J Respir Crit Care Med 150:1222-1228

McKeever TM, Scrivener S, Broadfield M et al (2002) Prospective study of diet and decline in lung function in a general population. Am J Respir Crit Care Med 165:1299-1303

Murray CJL, Lopez AD (1996) Evidence-based health policy-lessons from the Global Burden of Disease Study. Science 274:740-743

Niedermann MS (2000) Infection and antibiotic treatment in acute exacerbations of chronic bronchitis. In Allegra L, Blasi F (eds) Mechanisma and Management of COPD exacerbations. Sprnger Verlag Italia, Milano, pp 73-87

Niewoehner DE, Erbland ML, Deupree RH et al (1999) Effect of systemic glucocorticoids on exacerbations of Chronic Obstructive Pulmonary Disease. N Engl J Med 340:1941-1947

O'Donnell DE, Forkert L, Webb KA (2001) Evaluation of bronchodilator responses in patients with "irreversible" emphysema. Eur Respir J 18:914-920

O’Donnell DE, Lam M, Webb KA (1999) Spirometric correlates of improvement in exercise performance after anticholinergic therapy in Chronic Obstructive Pulmonary Disease. Am J Respir Crit Care Med 160:542-549

O'Donnell DE (2000) Assessment of bronchodilator efficacy in symptomatic COPD. Chest 117:42S-47S

Paggiaro PL, Dahle R, Bakran I et al (1998) Multicentre randomised placebo-controlled trial of inhaled fluticasone propionate in patients with chronic obstructive pulmonary disease. International COPD Study Group. Lancet 351:773-780

Pauwels RA, Lofdhal CG, Aitinen AA et al (1999) Long-term treatment with inhaled budesonide in persons with mild Chronic Obstructive Pulmonary Disease who continue smoking. N Engl J Med 340:1948-1953

Prescott E, Lange P, Vestbo J (1999) Socioeconomic status, lung function and admission to hospital for COPD: results from the Copenhagen City Heart Study. Eur Respir J 13:1109-1114

Repine JE, Bast A, Lankhorst I (1997) Oxidative stress in Chronic Obstructive Pulmonary Disease. Am J Respir Crit Care Med 156:341-357

Saetta M, Turato G, Maestrelli P (2001) Cellular and structural bases of Chronic Obstructive Pulmonary Disease. Am J Respir Crit Care Med 163:1304-1309

Santus P, Pecchiari M, Carlucci P et al (2003) Bronchodilation test in COPD: effect of inspiratory manoeuvre preceding forced expiration. Eur Respir J 21:82-85

Schols AM, Soeters PB, Dingemans AM et al (1993) Prevalence and characteristics of nutritional depletion in patients with stable COPD eligible for pulmonary rehabilitation. Am Rev Respir Dis 147:1151-1156

Siafakas NM, Tzortzaki EG, Sourvinos G et al (1999) Microsatellite DNA instability in COPD. Chest 116:47-51

Sin DD, Man SFP (2003) Inhaled corticosteroids and survival in chronic obstructive pulmonary disease: does the dose matter? Eur Respir J 21:260-266

Smith CA, Harrison DJ (1997) Association between polymorphism in gene for microsomal epoxide hydrolase and susceptibility to emphysema. Lancet 350:630-633

Soriano JB, Vestbo J, Pride NB et al (2002) Survival in COPD patients after regular use of fluticasone propionate and salmeterol in general practice. Eur Respir J 20:819-825 
Tager IB, Segal MR, Speizer FE, Weiss ST (1988) The natural history of forced expiratory volumes. Effect of cigarette smoking and respiratory symptoms. Am Rev Respir Dis 138:837-849

Terzano C, Mannino F (1997) Aerosol - Caratteristiche, analisi, applicazioni terapeutiche. McGraw-Hill, Milano

Terzano C (1999) Applicazioni mediche degli aerosol: dalla fisiopatologia all'azione terapeutica. Momento Medico, Salerno

Terzano C, Petroianni A, Ricci A, Allegra L (2005) Combination therapy in COPD: different response of COPD stages and predictivity of functional parameters. Eur Rev Med Pharmacol Sci 9:209-215

Terzano C, Allegra L (2002) Importance of drug delivery system in steroid aerosol therapy via nebulizer.Pulm Pharmacol Ther 15:449-454

The COPD Guidelines Group of the Standards of Care Committee of the BTS (1997) Guidelines for the management of chronic obstructive pulmonary disease. Thorax 52:S1-S28

The Lung Health Study Research Group (2000) Effect of inhaled triamcinolone on the decline in pulmonary function in Chronic Obstructive Pulmonary Disease. N Engl J Med 343:1902-1909

Turato G, Zuin R, Saetta M (2001) Pathogenesis and pathology of COPD. Respiration 68:117-128

Van Balkom, RHH, Zhan WZ et al (1997) Corticosteroid effects on isotonic contractile properties of rat diaphragm muscle. J Appl Physiol 83:1062-1067

van Noord JA, de Munck DRAJ, Bantje TA (2000) Long-term treatment of chronic obstructive pulmonary disease with salmeterol and the additive effect of ipratropium. Eur Respir J 15:878-885

Vestbo J, Sørensen T, Lange P (1999) Long-term effect of inhaled budesonide in mild and moderate chronic obstructive pulmonary disease: a randomised controlled trial. Lancet 353:1819-1823 